\title{
Biodegradable Nanomats Produced by Electrospinning: Expanding Multifunctionality and Potential for Tissue Engineering
}

\author{
N. Ashammakhi, ${ }^{1}$, A. Ndreu², A. M. Piras ${ }^{3}$, L. Nikkola , T. Sindelar ${ }^{4}$, H. Ylikauppila ${ }^{1}$, A. Harlin ${ }^{5}$, \\ M. E. Gomes, N. M. Neves, E. Chiellini ${ }^{3}$, F. Chiellini, V. Hasirci², H. Redl ${ }^{4}$, and R. L. Reis \\ ${ }^{1}$ Institute of Biomaterials, Tampere University of Technology, Tampere, Finland \\ ${ }^{2}$ Biotechnology Research Unit, Department of Biological Sciences, Middle East Technical University, Ankara, Turkey \\ ${ }^{3}$ Department of Chemistry and Industrial Chemistry, University of Pisa, Pisa, Italy \\ ${ }^{4}$ Ludwig Boltzmann Institute for Experimental and Clinical Traumatology, Vienna, Austria \\ ${ }^{5}$ Institute of Fiber Materials Science, Tampere University of Technology, Tampere, Finland
}

\begin{abstract}
With increasing interest in nanotechnology, development of nanofibers ( $n$-fibers) by using the technique of electrospinning is gaining new momentum. Among important potential applications of $n$-fiber-based structures, scaffolds for tissue-engineering represent an advancing front. Nanoscaffolds ( $n$-scaffolds) are closer to natural extracellular matrix (ECM) and its nanoscale fibrous structure. Although the technique of electrospinning is relatively old, various improvements have been made in the last decades to explore the spinning of submicron fibers from biodegradable polymers and to develop also multifunctional drug-releasing and bioactive scaffolds. Various factors can affect the properties of resulting nanostructures that can be classified into three main categories, namely: (1) Substrate related, (2) Apparatus related, and (3) Environment related factors. Developed $n$-scaffolds were tested for their cytocompatibility using different cell models and were seeded with cells for to develop tissue engineering constructs. Most importantly, studies have looked at the potential of using $n$-scaffolds for the development of blood vessels. There is a large area ahead for further applications and development of the field. For instance, multifunctional scaffolds that can be used as controlled delivery system do have a potential and have yet to be investigated for engineering of various tissues. So far, in vivo data on $n$-scaffolds are scarce, but in future reports are expected to emerge. With the convergence of the fields of nanotechnology, drug release and tissue engineering, new solutions could be found for the current limitations of tissue engineering scaffolds, which may enhance their functionality upon in vivo implantation. In this paper electrospinning process, factors affecting it, used polymers, developed $n$-scaffolds and their characterization are reviewed with focus on application in tissue engineering.
\end{abstract}

Keywords: Drug Release, Electrospinning, Multifunctional, Nanofiber, Nanotechnology, Regeneration, Scaffold, Tissue Engineering.

\section{CONTENTS}

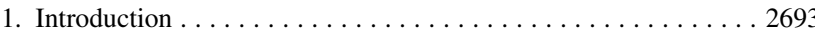

2. Electrospinning . . . . . . . . . . . . . . . . . . . . 2697

2.1. Evolution and Principle .................... 2697

2.2. Factors Affecting $e$-Spinning . . . . . . . . . . . . . . 2697

3. Development of Biodegradable Nanomats . . . . . . . . . . 2699

3.1. General . . . . . . . . . . . . . . . . . . . . . . . 2699

3.2. Developed Nanomats . . . . . . . . . . . . . . . . . . 2701

3.3. Characterization of Nanomats . . . . . . . . . . . . 2703

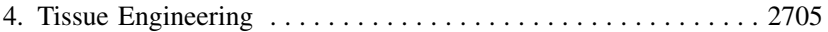

4.1. Cardiovascular Tissues . . . . . . . . . . . . . . . . . 2705

4.2. Skin and Mucosal Tissue ................... 2706

${ }^{*}$ Author to whom correspondence should be addressed.
4.3. Neural Tissue . . . . . . . . . . . . . . . . . . . . . . . 2706

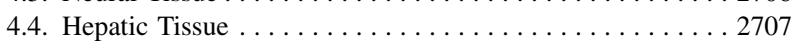

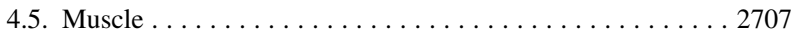

4.6. Ligament/Tendon . . . . . . . . . . . . . . . . . . . . 2707

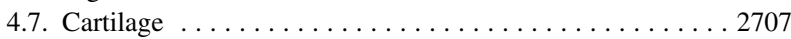

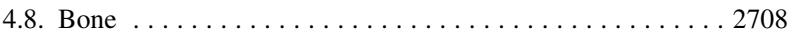

5. Future Prospects . . . . . . . . . . . . . . . . . . . . . . . 2709

Acknowledgements ............................ 2709

References and Notes . . . . . . . . . . . . . . . . . . . . . . . 2709

\section{INTRODUCTION}

Nanotechnology is expanding through extensive research after it has gained more attention, popularization and 
funds. An important target of nanotechnology is the development of biomaterials that have improved physical, chemical and biological properties. ${ }^{1}$ Developments in nanotechnology are dependent on parallel progress made in processing methods. ${ }^{2,3,4,5}$ This will allow devices based on nanomaterials to become more sophisticated and successful. Major advances represent the development of nanoparticles for various medical applications that involve diagnosis, treatment and assessment of prognosis. ${ }^{6}$ Another important advance is the exploitation of nanofiber ( $n$-fiber) based materials in drug delivery and in tissue engineering as biomimetic matrices. Such matrices should be porous, fibrous and be capable of storage and delivery of necessary signaling molecules. In our previous studies on cartilage tissue engineering we have observed that better cartilage formation was observed with thinner fibers
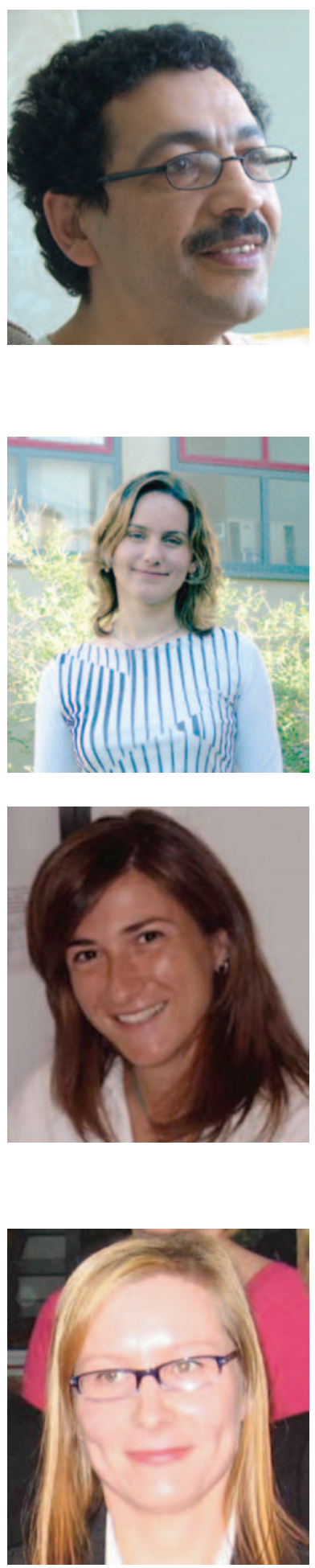

Nureddin Ashammakhi, M.D., Ph.D., is a professor and Vice Director of the Institute of Biomaterials, Tampere University of Technology, Tampere, Finland and a Docent at the University of Oulu, Oulu, Finland. His main work is focused on developing, investigating, and transferring biodegradable biomaterials technology to the clinic and industry. An important focus of the research of his team includes drug release and tissue engineering. Target areas of applications include bone and cartilage. The convergence of areas such as nanotechnology and drug release is being explored to advance regenerative medicine. The work of Ashammakhi's team has gained international recognition and attracted funds from major funding agencies such as the European Commission. He is a reviewer of many journals in the filed and expert consultant of funding agencies, academia, and industry. He's also established an open-access series of e-books "Topics in Tissue Engineering" to share knowledge in the field with all, all over the globe.

Albana Ndreu, was born in Albania 2nd August 1979. She is a M.S. student at the Biotechnology Programme of the Middle East Technical University (METU). Her main research areas are nanotechnology and tissue engineering. Her publications (original) is Electrospun Biodegradable Nanomats for Tissue Engineering, Biomaterials (Submitted) and Poster Presentation are Nanofibres Prepared Using Electrospinning-Tissue and Cell Engineering Society 2006, Annual Meeting (TCES 2006), Sheffield, U.K. and Electrospun Biodegradable Nanofibers as a Tissue Engineering Candidate-NanoScience and NanoTechnology 2006 (Nano TRII), Ankara, Turkey, 2006.

Anna Maria Piras obtained Laurea Degree in 2002 in Chemistry and Pharmaceutical Technology University of Pisa after been a visiting student at the Department of Biochemistry, University of Minnesota in Minneapolis (USA). In the same year she joined Kedrion S.p.A., Castelvecchio Pascoli, Lucca as junior researcher in the field of drug delivery. In 2003 she was appointed as a Ph.D. student in Biomaterials at the University of Pisa and in the year 2006 defended a Thesis on the "Polymeric micro- nano-particles and electrospun fibers in regenerative medicine applications." In 2005 she was visiting Ph.D. student at the Institute of Biomaterials, Tampere University of Technology, Tampere, Finland. Since 2006 she works at the University of Pisa as post-doctoral fellow. Her main research interests are on the formulation and characterisation of bioerodible/biodegradable devices for biomedical applications. She is a co-author of 3 publications and 15 contributes to national and international conferences.

Lila Nikkola is graduated on 1995 from Tampere Polytechnic (Health Care) as a Bioanalyst. She worked as bioanalyst in Tampere University/Institute of Medical Technology/Cancer Genetics and Tampere University hospital/Research Laboratory of Molecular Pathology over all four years having one child during and one after that time. She has been working in Tampere University of Technology/Institute of Biomaterials since 2003, first as a summer trainee and later as a master's thesis worker. After graduation she continued in the Institute as a researcher and post graduate student. Currently, she is project manager in three projects. Her main research areas are drug release, nanotechnology, and multifunctional implants in fields of tissue engineering and reconstruction, and cancer treatment. She published six research articles and presented three articles in ICAB 2006, FiberMed 06, ESB 2005, respectively. 

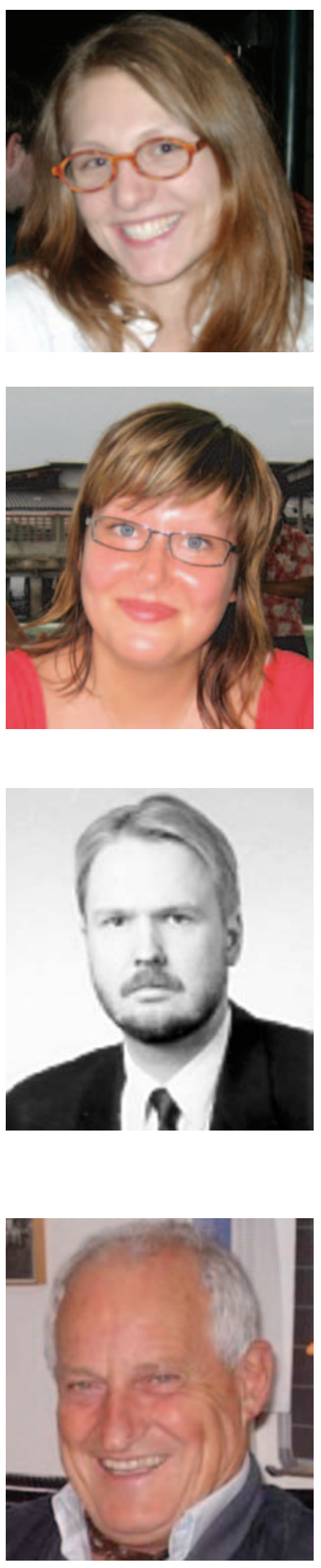

Hanna Ylikauppila, was born in Oulainen 23rd of June 1982. She graduated from high school on May, 2001. After that she started to study Materials Sciences in Tampere University of Technology and graduated on April, 2006. Biomaterials was her major subject, as minor subjects she studied materials chemistry and polymer composites. She has worked as a research student in Tampere University of Technology/Institute of Biomaterials for the summer 2003 and 2004, and also from September, 2004-March, 2005. Then in the spring April, 2005 she started to do her Master of Science Thesis in the Institute of Biomaterials. After graduating she continued working in the Institute as a researcher and doing her post graduate studies. To date, she works as a researcher in two projects. Her main research areas are drug release, nanotechnology, and bioactive implants in fields of tissue engineering and reconstruction, biomedical bone applications, and cancer treatment.

Ali Harlin was born 1963 in Helsinki, Finland. He received M.Sc. degree in Chemical Engineering (Polymer Science) in 1987 and the degree of Dr. Tech. in Polymer Technology (Extrusion technology) in 1996 at Helsinki University of Technology. During his doctoral studies he worked with polyolefin manufacturing and applications in Borealis (former NESTE Chemicals) as a project and development manager, and since 1997 he joined cable machinery development in Nokia-Maillefer as General Manager, Technology and Development, and till 2000 as Managing Director of Conex Cables. Finally in 2001 he was nominated Professor of fibre material science in Tampere University of Technology, 2003 docent of electric insulating materials in Helsinki University of Technology, and 2004 Professor of smart materials in VTT Technical Research Centre of Finland. Recently, Prof. Harlin has been nominated Director Composite and Packaging Materials in KCL Central Laboratory in Finland.

Dr. Emo Chiellini since 1980 is full professor of Chemical Principles of Technologies at the Faculty of Engineering of the University of Pisa. In 1963 he graduated at the University of Pisa with a thesis in Polymer Science in the group of Prof. Piero Pino. Since then he continued his activity in Polymer Science and Technology at the Department of Chemistry and Industrial Chemistry of the University of Pisa as well as visiting scientist at the University of Liverpool (U.K.), University of Massachusetts at Amherst (USA) and University of Nagasaki (Japan). He is presently head of an interdisciplinary research group active in Polymer Science and Technology with specific interest in the field of Bioactive Polymeric Materials for Biomedical, Pharmaceutical, and Environmental Applications. He has served and currently is serving as member of the Editorial Boards of various scientific journals related to Polymer Science and Technology including among the others Reactive Polymers, Macromolecules, Korea Polymer Journal, Biomacromolecules, Polymer Degradation and Stability, Journal of Bioactive Polymers, Journal of Polymers and Environment. He has chaired international conferences related to Polymers in Medicine, Liquid Crystalline Polymers, Biodegradable Polymeric Materials and Plastics and a prestigious Gordon Research Conference on Biodegradable Polymers in 1996. He is author and co-author of more than 400 publications in peer-reviewed journals, 20 books, and 20 patents. The research group leaded by Prof. Chiellini is active in multipartner projects funded by Industries, Italian Ministry of University and Research, and European Community. He is currently acting as advisor in a research program on Sustainable Polymeric Materials and Environmentally Degradable Polymers launched by the International Center for Science and High Technology under the UNIDO sponsorship. 

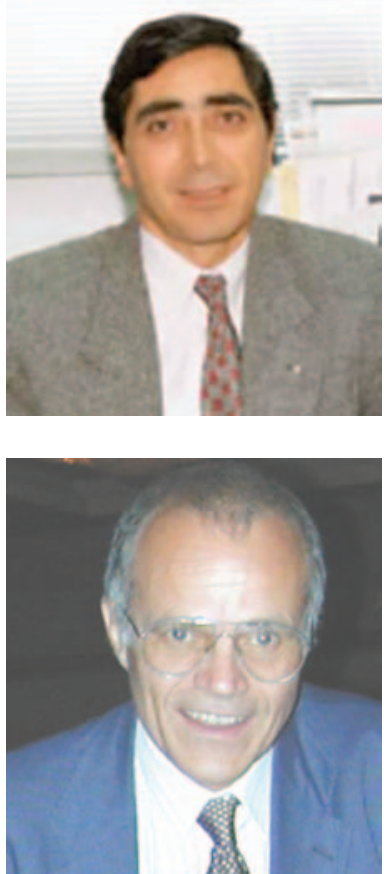

Dr. Vasif Hasirci is a professor, received his M.S. degree on 1973. He got his Ph.D. degree on 1976 from University of Reading. His current research areas are Biomaterials: Hydrogels, controlled drug (antibiotic and pain reliever) delivery, photodynamic liposomes, tissue engineering (bone, cartilage, retinal pigment epithelial cells, cornea, nerve, cardiac tissue), biodegradable polymers, hard tissue repair, enzyme immobilization, Biotechnology: Biosensors, bioreactors, biodegradation of pesticides. He refreed seven international journals and authored three books.

Heinz Robert Redl, born 1952, attended the Technical University Vienna and graduated in Technical Biochemistry. He first worked as an Research Assistant and later on as Assistant Professor at the Technical University Vienna at the Institute for Technical Microscopy. Since 1982, he has been working as an Associated Professor at the Technical University. Next to his teaching he has been consulting not only Baxter Bioscience/Biosurgery but also the Research Institute for Traumatology of AUVA (Austrian Workers Compensation Board) since the late 1970 up to today. In 1980, he started to work as Research Scientist at the Ludwig Boltzmann Institute for Experimental and Clinical Traumatology in Vienna, where he became Deputy Director in 1995. Since 1998, he is Director of the Ludwig Boltzmann Institute for Experimental and Clinical Traumatology in Vienna as well as the Trauma Care Consult, which he founded in the same year. Next to his activities in research areas, he is also a member of the Editorial Board of Shock and European Journal of Trauma, past president of the European Shock Society and a council member of the Federation of the International Shock Societies.

(Unpublished data). Thus, we pursued approaches to produce thin fibers for better chances of success in tissue engineering. To produce fibers, phase separation, $, 2,8$ template synthesis, ${ }^{4}$ bi-component [islands-in-the-sea (INS) structure] drawing, ${ }^{5}$ self-assembly, ${ }^{9}$ or electrospinning $^{3,10-14}$ and combinations thereof ${ }^{15}$ can be used. Each of these methods has its own advantages and disadvantages. Phase separation can be used to produce nanoporous foams, which are preferred in many areas. However, the problem is that long time is needed to complete the whole process. The same thing applies for self-assembly process due to the need of thermodynamic equilibrium in solution. Although, self-assembly can produce much thinner $n$-fibers than those that can be produced by $e$-spinning, self-assembly requires much more complicated procedures and extremely elaborate techniques and it is of low productivity. ${ }^{16}$ Solid or hollow fibers can be obtained by means of template synthesis, but it does not produce one-to-one continuous fibers. Drawing process is limited by the fact that only viscoelastic materials which can withstand applied stresses during the process can be used. The problem can be overcome by multicomponent spinning of INS structures combined with detachment of submicron fibers, with reasonable cost but unfortunately this results in the formation of coarse fibers (diameter larger than $500 \mathrm{~nm}$ ) compared to other methods. On the other hand, electrospinning (e-spinning) is more economical, simpler, yields continuous fibers, and is versatile enough to be applied to a variety of materials. $e$-spinning is also the least expensive method used to manufacture $n$-fibers. ${ }^{17}$ Furthermore, $n$-fibers can be obtained with by using very small amounts of polymeric solutions. $e$-spinning offers a simple and versatile method for generating ultra-thin fibers from a wide range of materials that include polymers, composites and ceramics. ${ }^{18}$

$e$-spinning results in fibers with a diameter range from $3 \mathrm{~nm}$ to several micrometers whereas the abovementioned other methods produce fibers with diameters ranging from $500 \mathrm{~nm}$ up to a few micrometers and their fibers are only a few micrometers long. ${ }^{14}$ Accordingly, $e$-spinning is a suitable process for manufacturing $n$-fibers for biomedical applications such as drug release ${ }^{19-29}$ or tissue engineering. ${ }^{13,29-43}$

In $e$-spinning, resulting fiber diameter and alignment, etc., can be controlled by manipulating processing parameters $^{33}$ (See below). The principle of $e$-spinning is based on exploiting the forces acting upon a solution droplet. An electrically charged polymer solution forms at the tip of syringe. On one side, surface tension tends to keep falling droplets of the polymeric solution and on the opposite side, electric forces act to pull the droplet. As the voltage applied is increased, the droplet in the tip of the syringe elongates more and more until the formation of a hyperbolic cone ${ }^{44}$ (also called Taylor cone after Taylor who has performed fundamental investigations on the jet formation $)^{45}$ occurs. The $e$-spinning process has three stages: ${ }^{46}$

(a) initiation of the jet and the extension of the jet along a straight path;

(b) the growth of a bending instability and further elongation or drawing of the jet that allows it to move in looping and spiraling path;

(c) solidification of the jet into $n$-fibers. 
In a typical $e$-spinning apparatus, the polymer solution is contained in a syringe or a glass capillary. When an electric field is applied to a polymer solution, ions in the solutions aggregate at the surface of suspended liquid/solution drop at the tip of the capillary, and the droplet starts to act as an electrode. ${ }^{47}$ When the electric field increases, the meniscus elongates to form a conical configuration (Taylor Cone), until at critical value of the electric field, surface tension can no longer balance the hydrostatic and electric forces and a thin jet is ejected form the surface of the meniscus towards the nearest electrode of opposite polarity, or electrical ground. ${ }^{48}$ After initiation, the jet travels in straight line for typically about $0.02-0.03 \mathrm{~m}$, after which electrically driven instability is triggered by the perturbations of the lateral position and lateral velocity of the jet, causing bending, winding, spiraling, and looping path in three dimensions. The whipping jet was observed by a high speed camera. ${ }^{49}$ Finally, the jet splits into charged $n$-fibers that accumulate on collecting metal screen (counter-electrode) ${ }^{50}$ During this period the solvent evaporates and gives rise to the desired fibrous form. Due to repulsive forces, produced $n$-fibers accumulate on the collecting system in the form of three-dimensional (3D) interconnected web. ${ }^{47}$ Most typical defect in fiber formation is the so called Rayleigh instability ${ }^{51}$ forming pearls distributed along the fiber length. The greater the distance the fiber needs to travel, the thinner it becomes. The distance that a fiber travels does influence how much of the solvent evaporates. Under specific operation conditions, which are not typical for the process, it is observed that joining loops and fragmentation of fibers occurs leading to the formation of irregular shapes of fibers. ${ }^{52}$ Applied modeling of the process was developed in the recent years ${ }^{53,54}$ but an engineering model that can enable process control has not been established yet. The process may occur either at room temperature or inside a fume chamber depending on the used polymer and solvent type. $e$-spinning without solvent is also possible by using melt polymers in a vacuum chamber. ${ }^{55}$ However, the process still needs more exploration and development to be of benefit on commercial large scale production level. In the current paper we review published reports on biodegradable nanomats produced by $e$-spinning, both as plain and as multifunctional bioactive and active molecule releasing scaffolds with potential use in tissue engineering.

\section{ELECTROSPINNING}

\subsection{Evolution and Principle}

The development of the industrial technique of $e$-spinning dates back to early in last century. ${ }^{56}$ Formalas was the first to develop some patents on apparatus and process of how filaments can be produced by means of electric fields. ${ }^{57-61}$ The term 'electrospinning' was introduced around 1994. There was especially an increase in publications after 1998

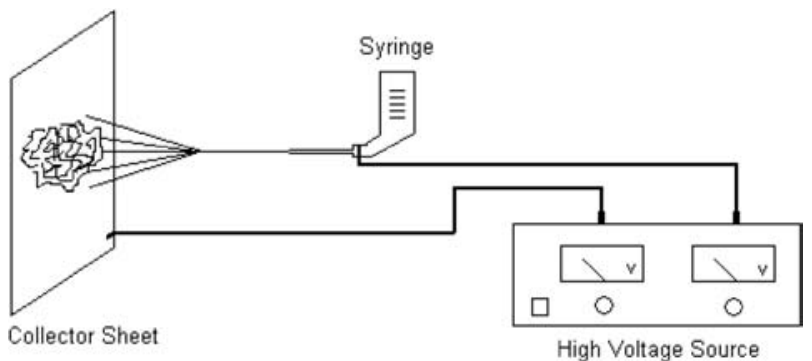

Fig. 1. Schematic illustration of electrospinning set-up showing the main three compartments of the $e$-spinning system: (A) syringe, (B) voltage supplier, and (C) collector.

of with the largest number being from USA. ${ }^{51} e$-spinning process has seen a great revival as nanotechnology became popularized.

In $e$-spinning, a voltage supplier with a wide range of tens of kilovolts, a glass syringe with a small needle and a metal-made collector are the main three compartments (Fig. 1). Typical conditions are in the range of $10-50 \mathrm{kV}$ potential difference typically from positive to ground, but also from negative to positive with, e.g., regenerated celluloses, with deposition distance of 100-350 mm. Polymer solutions having viscosity of 100-3000 centipoises are used. Productivity of one nozzle is typically $3-10 \mathrm{ml} / \mathrm{h}$ of solution containing 2-25 wt $\%$ of polymer, markedly depending on the molecular weight and type of polymer and solvent system.

\subsection{Factors Affecting $e$-Spinning}

\subsubsection{General}

The science of electrically driven jets and electrically charged particles was developed by pioneers over three centuries. Bose developed an aerosol spray by applying a high potential to a liquid in the end of glass capillary already in $1745 .{ }^{62}$ Later, Lord Rayleigh studied the instabilities that occur in electrically charged droplets concluding the possibility of fiber drawing. ${ }^{63}$ Zeleney studied the role of surface instability in electrical discharges from charged droplets and provided theoretical relations for instability which were satisfied when the discharge of the jet began. ${ }^{64}$ Vonnegut and Neubauer generated boundary conditions for uniform streams of highly charged droplets. ${ }^{65}$ Finally, Taylor analyzed the conditions at which the point of a droplet deforms to conical shape, the Taylor Cone, and showed how both conductivity and viscosity play an important role in the process. ${ }^{66}$ The influence of the experimental conditions on the morphology and stability of the $e$-spun fibers were performed by Hayati ${ }^{67}$ and Doshi. ${ }^{50}$ Factors that can influence $e$-spinning ${ }^{68,69}$ can be summarized into three main categories:

(1) those related to substrate solution (polymer type and concentration, solution dielectric constant, conductivity, and surface tension), 
(2) apparatus related factors (flow rate of the solution, hydrostatic pressure in the spinnerette, applied electric field, and tip-collector distance), and

(3) environmental factors (temperature, humidity, air velocity in the spinning chamber).

A correct setting of $e$-spinning parameters should allow for producing average thin fibers with narrow variations in diameter.

Modified technologies and apparatus were developed for the production of advanced structures. For instance, scanning tip electrodes orient formed $n$-fibers, but they can be used also for increased uniformity especially on planar nanocoatings. ${ }^{70} e$-spinning can be performed on a rotating electrode with multiple nozzle systems to form oriented and 3D shaped constructions. ${ }^{71}$ Four cross located electrodes can be used to produce a mesh. ${ }^{72}$ Finally, the pattern of multiple electrodes can form any structure or pattern on a flat substrate enable the development of even printinglike results.

\subsubsection{Substrate-Related Factors}

When low molecular weight polymers are used, instead of "electrospinning" it is "electrospraying" that occurs when the onset of instability of process results in a spray of small charged droplets. ${ }^{68,73}$ The ability to spin fibers, blow films and perform other polymer processing operations on a material relies on the onset of entanglements between chains. It usually occurs at a molecular weight where a number of loops of the chain could possibly occur, which is about $10,000 \mathrm{~g} / \mathrm{mole}$. Electrospraying occurs, when entanglement of polymer chains does not occur but still undergoes a bending instability that causes a whip-like motion between the capillary tip and the grounded target. ${ }^{74}$ All properties that can be related to the entire chain, are affected by entanglements. ${ }^{75}$ Apart from molecular weight and molecular weight distribution, other thermodynamic properties, e.g., crystallization and glass transition temperature have also effect on processing and resulting $n$-fibers. ${ }^{76-78}$ The architecture of the polymer also affects processing. In $e$-spinning, branched polymers seem to need higher concentration than linear polymers to obtain defect free $n$-fibers. ${ }^{79}$

Most of studies have revealed that increasing the concentration of polymer in the solution is accompanied with an increase in fiber diameter and decrease in bead forma-

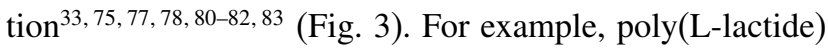
[PLLA] fiber diameter was found to increase with increasing polymer concentration, from $150-500 \mathrm{~nm}$ for $2 \%$ of PLLA concentration to $800-3000 \mathrm{~nm}$ for $5 \%$ of PLLA. ${ }^{13}$

Regarding solvents, a highly volatile solvent is more preferable but this may change according to the purpose of processing. Chun et al. ${ }^{84}$ have investigated the effect of two different solvents (isopropyl alcohol and dimethylacetamide) on $e$-spinning of poly(ethylene-co-vinyl alcohol) $[\mathrm{EVOH}]$ and it was concluded that the presence of hydrogen bondings can affect fiber diameter and morphology. ${ }^{84}$ In our experiments, ${ }^{83}$ we have looked at two different solvents (acetic acid and ethanol). Since ethanol has a surface tension $\left(22.4\right.$ dynes $\left.\mathrm{cm}^{-1}\right)$ lower than acetic acid $\left(28\right.$ dynes $\left.\mathrm{cm}^{-1}\right)$, easier evaporation of ethanol as compared to acetic acid may have let to the formation of thicker fibers. In another report, Fong et al. ${ }^{85}$ found that high surface tension leads to the formation of beads rather than fibers. In addition, ethanol has a dielectric constant of $24.3 \mathrm{C}^{2} \mathrm{~m}^{-2} \mathrm{~N}^{-1}$ at $25{ }^{\circ} \mathrm{C}$, whereas acetic acid has a constant of $6.2 \mathrm{C}^{2} \mathrm{~m}^{-2} \mathrm{~N}^{-1}$ at $20{ }^{\circ} \mathrm{C}$. Related to this, Lee et al. ${ }^{77}$ indicated that the electrolytic tendency of the solvent can be the most important parameter of $e$-spinning process. Various $n$-fiber surface morphologies, e.g., of $e$-spun PLLA $n$-fibers have been produced. A variety of size and orientation of nanopores have been produced in the range of $5.5-9.8 \mathrm{~nm}$ on the $n$-fibers by using a variety and mixtures of solvents. ${ }^{78}$

It was observed that the addition of salt to polymer solutions undergoing $e$-spinning results in the formation of fibers thinner than those made from solutions containing no salt. This can be explained to occur as a result of an increase in the charge density, which brings more elongating forces acting on the polymeric solution and therefore result in the formation of thinner and more straight fibers. ${ }^{85}$ Choi et al. ${ }^{12}$ have demonstrated that conductivity of poly(3-hydroxybutyrate-co-3-hydroxyvalerate) (PHBV)-6 polymer can be improved by addition of some salt like benzyl triethylammonium chloride (BTEAC). We have also observed the effect of this salt on $e$-spun PHBV-8 fiber morphology. ${ }^{82}$ PHBV-8 fiber structure that was produced from solutions containing no salt had resulted in bead formation and fibers were not straight. When salt was added, bead formation was prevented and more straight fibers were obtained ${ }^{82,86}$ (Fig. 2). In other experiments ${ }^{83}$ the drug diclofenac was used in its sodium salt form (DS). It was observed that with the addition of DS to polymer dissolved in acetic acid, thinner fibers were obtained. Similar observations were made when

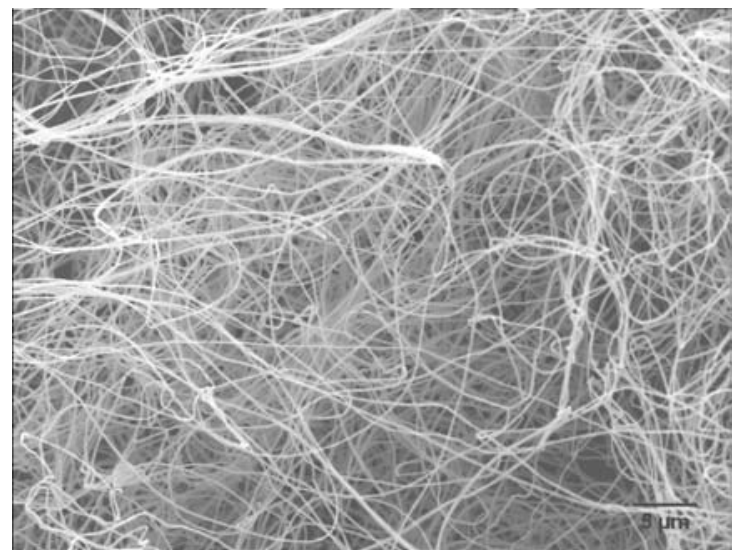

Fig. 2. Electrospun nanomats made of PLGA 80/20 that was dissolved in chloroform at a concentration of 5\%. Average fiber diameter was $1 \mu \mathrm{m}$. 
(A)

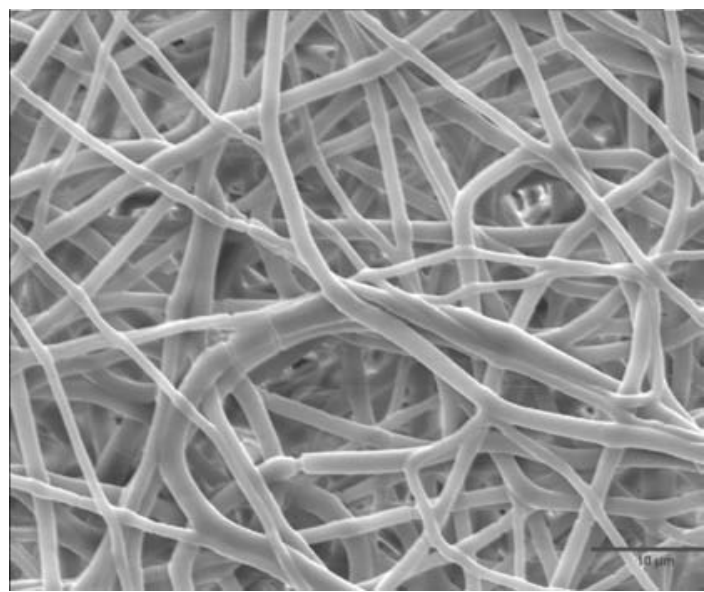

(B)

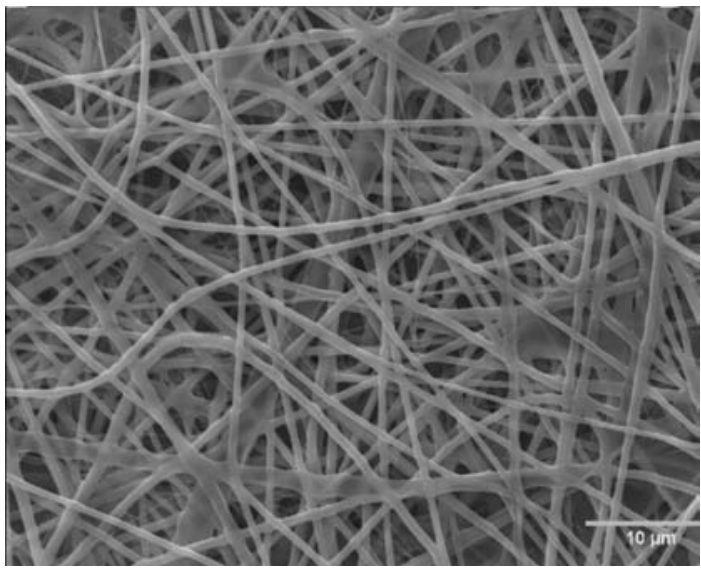

Fig. 3. Effect of benzyl triethylammonium chloride (BTEAC) salt addition on fiber morphology (A) $e$-spun nanomats made from poly(hydroxybutyrate-co-3-hydroxyvalerate) copolymer having $8 \%$ hydroxyvalerate (PHBV-8) solution that contained no salt; (B) $e$-spun nanomats made from PHBV-8 solution that contained 2\% BTEAC salt (Original magnification $\times 1000)$. Note that when salt was used, nanofibers become more straight and homogenous diameter with fewer strictures are obtained.

cefoxitin sodium ${ }^{23}$ was added to poly(lactide-co-glycolide) (PLGA) polymer solutions, or when salts like $\mathrm{NaH}_{2} \mathrm{PO}_{4}$, $\mathrm{KH}_{2} \mathrm{PO}_{4}$, and $\mathrm{NaCl}$ were added to poly(D/L-lactide) (PDLLA) solutions. ${ }^{20}$ Lee et al. demonstrated that processing polyvinyl chloride (PVC) dissolved in different mixtures of tetrahydrofuran (THF) (dielectric constant 7.6 at $25^{\circ} \mathrm{C}$ ) and $\mathrm{N}, \mathrm{N}$-dimethylformamide (DMF) (dielectric constant 36.7 at $25{ }^{\circ} \mathrm{C}$ ), viscosity and surface tension of the solution have changed. Thickest fibers were obtained with THF and thinnest ones with DMF solvent. ${ }^{77}$

\subsubsection{Apparatus-Related Factors}

The flow rate of polymer solution is caused by the force of applied electric field, ${ }^{87}$ gravity, ${ }^{56}$ and possible use of pump. ${ }^{12}$ Zong et al. ${ }^{20}$ reported that lower volumetric feed rates of solution that was delivered to the needle resulted in slightly smaller fiber diameters due to faster solvent evaporation. ${ }^{20}$ However, Megelski et al. ${ }^{78}$ demonstrated that the formation of thicker $e$-spun polystyrene fibers with higher flow rates was also possible. The size of the needle has also an effect on fiber diameter. It was reported that smaller needle orifice contributes to formation of smaller fiber diameters. ${ }^{80}$

Applied voltage has been found to have crucial effects on $e$-spinning. ${ }^{68,84,80}$ For example, the morphology of $e$-spun PEO nanofibers changed from being straight, defect-free fibers when spun at an initiating voltage of $5.5 \mathrm{kV}$, to fiber mats containing a high density of beads when spun at an initiating voltage of $9.0 \mathrm{kV}{ }^{68}$ Increase in voltage is may decrease fiber diameter. ${ }^{80}$ However, above certain level the increase of voltage does not have significant effect on fiber diameter. ${ }^{80} \mathrm{~A}$ hypothesis for this was presented and it implies that thinner $n$-fibers can be obtained by using smaller needles due to smaller base of Taylor cone and consequent thinner ejected jet. ${ }^{80}$ However, the difference was significant only between 16- and 20 -gauge needles. ${ }^{80}$

Short distances between needle and collector can be used when a highly volatile solvents is employed. Solvents possessing low vapor pressure, e.g., water need longer distance for the evaporation of solvent. In addition, the distance between needle tip and collector has effect on fiber morphology and diameter. Decrease in distance, regardless of the concentration of polymer solution, results in the formation of wet fibers and beaded structure. ${ }^{69,77}$ Moreover, the shape of fibers changes from round to flat when the distance is decreased. ${ }^{69}$

\subsubsection{Environmental Factors}

Environmental factors like temperature, humidity, and air velocity in the $e$-spinning chamber have to be well controlled to obtain similar fibers every time. Increase of solution temperature has an effect on chain formation in solution, decrease in the viscosity of solution, and increase of solvent evaporation. All mentioned factors influence fiber morphology. Demir et al. ${ }^{88}$ noticed that $e$-spinning polyurethane at elevated temperature resulted in smaller diameter distribution than fibers $e$-spun at room temperature. They noticed also that it was possible to $e$-spin solutions having higher concentrations when the temperature is elevated. On the other hand, Casper et al. ${ }^{89} e$-spun polystyrene fibers in atmosphere with greater than $30 \%$ relative humidity and they observed micro- and nanostructured pores in the surface of fibers. Optimizing the conditions in order to get the best results is a challenging task. Consequently, achieving reproducibility in this process is a difficult task but not unachievable.

\section{DEVELOPMENT OF BIODEGRADABLE NANOMATS}

\subsection{General}

Scaffolds for tissue engineering have to possess certain properties to enable successful engineering of tis- 
sue constructs in vitro and subsequent function upon implantation in vivo. Thus, degradation rates of scaffolds have to be tailored according to target application. Porosity should be appropriately high to allow for homing and population by cells in large numbers. Pores in the structure have to be interconnected in order to facilitate uniform distribution of cells, the diffusion of necessary nutrients in and waste products out.

Nanofibrous scaffolds can be prepared by methods like $e$-spinning. Generally, nanomats are characterized by having pores smaller than cells. They act rather as basement membranes over which cells can spread. In other studies, it was observed that cell appendages attach to $n$-fibers and cell aggregate embrace fibers. ${ }^{39,41}$ It might be beneficial to develop systems with large porosity to guide cell attachment and allow cell population ${ }^{41}$ as well as easy diffusion of nutrients and waste products.

Polymers that were investigated to develop biodegradable nanomats include natural, synthetic, and blends of the two $^{14,82}$ (Table I). For tissue engineering, bioabsorbable

Table I. List of biodegradable and bioerodible polymers that were used in $e$-spinning to produce $n$-fibers.

Polymer

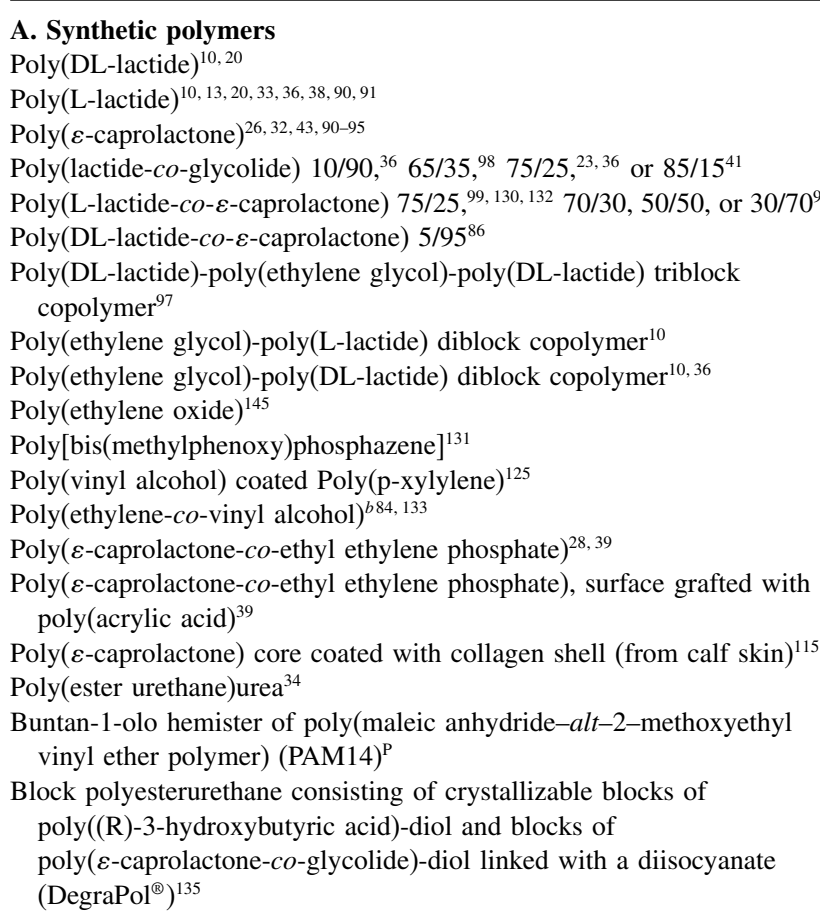

\section{B. Natural-derived polymers}

Silk fibroin ${ }^{29,103}$

Hyaluronic acid ${ }^{110}$

Cellulose ${ }^{146}$

Oxidised cellulose ${ }^{111}$

Hydroxypropylmethylcellulose ${ }^{24}$

Collagen type I (from calfskin ${ }^{93,101,147}$ or from human placenta ${ }^{101}$ )

Collagen type II (from chicken sternae) ${ }^{102}$

Collagen type III (from human placenta) ${ }^{101}$
Table I. Continued.

\section{Polymer}

Gelatin (denatured collagen from bovine skin) $)^{93}$

Solubilized alpha-elastin ${ }^{93}$

Tropoelastin (Recombinant human $)^{93}$

Chitin $^{148}$

Chitosan ${ }^{149}$

Polyhydroxybutarate valerate- $8^{82}$

Fibrin $^{32,108}$

Fibrinogen ${ }^{108}$

\section{Blends/Combinations}

PLGA 10/90 and PLLA $(75: 25 \mathrm{wt} \%)^{36}$

PLGA 25/75 and PEG-PDLLA (85:15 wt $\%)^{36}$

PDLLA, PLGA 50/50, PDLA- $b$-PEG- $b$-PDLA and Lactide

$(40: 25: 20: 15 \mathrm{wt} \%)^{137}$

PLGA, PEG- $b$-PDLA diblock copolymer and PLA (80:15:5 wt $\%)^{23}$

PCL/PVA combination ${ }^{139}$

Silk fibroin and poly(ethylene oxide) $)^{104}$

Cellulose and heparin ${ }^{146}$

Starch and PCL (30:70 wt \%) $)^{42,150}$

Poly(hydroxybutyrate-co-hydroxyvalerate) and P(L/DL)LA 70:30 (1:1) 82

Poly(hydroxybutyrate-co-hydroxyvalerate) and PLLA $(1: 1)^{82}$

Poly(hydroxybutyrate-co-hydroxyvalerate) and PLGA 75:25 (1:1 $)^{82}$

Poly(hydroxybutyrate-co-hydroxyvalerate) and PLGA 50:50 (1:1 $)^{82}$

Collagen type I and III (both from human placenta) 50:50 ${ }^{101}$

Collagen type I (from calf skin), elastin (from ligamentum nuchae), and poly(D,L-lactide-co-glycolide) $(45: 40: 15)^{35}$

Collagen (type I from calf skin), elastin (from bovine neck ligament) and poly(ethylene oxide) ${ }^{134}$

Collagen-chondroitin sulfate (96:4 and 90:10) $)^{114}$

Collagen (type I from calf skin) and poly(ethylene oxide) $)^{134}$

Collagen (type I from calf skin) and poly(L-lactide-co- $\varepsilon$-caprolactone) $70: 30(1: 1 \mathrm{w} / \mathrm{w})^{113}$

Collagen (type I from calf skin) and poly $(\varepsilon \text {-caprolactone })^{31}$

Collagen (type I from calf skin) and poly $(\varepsilon \text {-caprolactone })^{c 115}$

Gelatin (type B, bovine skin) and polyaniline $e^{a 151}$

Gelatin (type A, porcine skin) and poly $(\varepsilon \text {-caprolactone })^{152}$

Elastin (from calf bovine neck ligament) and poly(ethylene oxide) $)^{134}$

${ }^{a}$ Polyalinine is not biodegradable.

${ }^{b}$ Partially biodegradable.

${ }^{c}$ Coaxial spinning.

polymers are preferred because they can be employed to provide temporary scaffolding function for newly-forming tissue and to be subsequently replaced by native tissue with the polymer material getting removed by natural and metabolic processes of the body. Hence, no residual material that can act as focus of irritation with possible infection, is left in the body. It is also important for newly-formed tissues to take over by time and become independent of the supporting scaffold. This is especially important, e.g., in tissues like bone where physiological loading is crucial.

There are certain polymers that have been used for many years in surgery as implants, i.e., sutures, screws, and plates, and they represent good candidates to use as raw materials for producing nanomats for future use in the clinic. Thus, studied polymers (Table I) included PLLA, ${ }^{10,13,20,33,36,38,90,91} \quad$ PLDLA, $^{10,20} \operatorname{poly}(\varepsilon$-caprolactone) (PCL), ${ }^{26,32,43,90-95}$ and their copolymers such as PLGA $^{23,36,41,92,96-98}$ and poly( $\varepsilon$-capolactone-co-L-lactide) 
(PCL-PLLA) ${ }^{99}$ etc. These polymers have a wellcharacterized behavior in the body and defined elimination routes. Although $e$-spinning of natural polymers is more challenging, there are various reports already on developing nanomats from natural polymers. Polymers of natural origin that have been used to develop $n$-fibers, include collagen, ${ }^{31,93,100-102}$ silk protein, ${ }^{103-105}$ elastin, ${ }^{106}$ tropoelastic ${ }^{93}$ elastin-mimetic peptide, ${ }^{107}$ fibrinogen, ${ }^{108,} 109$ fibrin $^{32,108}$ hyaluronic acid, ${ }^{110}$ oxidized cellulose, ${ }^{111}$ and PHBV. ${ }^{82}$ Interesting enough, collagen type I $n$-fibers that were produced using $e$-spinning exhibited the 67-nm banding, which is seen in native collagen fibrils. ${ }^{101}$

In addition, smart polymers where bioerosion is dependent on $\mathrm{pH}$ have also been studied by our group. ${ }^{83}$ Combinations of synthetic and naturally-derived polymers were also used for combining properties of both. Studies involved PCL coated with gelatin, ${ }^{112}$ PCL-PLLA coated with collagen ${ }^{30}$ blends of silk and PEO, ${ }^{29}$ blends of collagen and PCL-PLLA, ${ }^{113}$ and blends of starch and PCL, ${ }^{42}$ etc. Our studies involved blends of PHBV with PDLLA, PLLA, or PLGA. ${ }^{82}$ Blends of natural polymers were also explored such as collagen and chondroitin sulphate. ${ }^{114}$

Mostly, nanomats produced by means of $e$-spinning have a nonwoven structure. However, developing aligned $n$-fibers has been one area of interest. For the production of aligned $n$-fibers, instead of using a stationary collector, a rotating collecting system is used. ${ }^{51}$ We have developed so far aligned $n$-fibers by using a rotating cylinder. ${ }^{82}$ Aligned fibers are important to guide regeneration of tissues like neural, ${ }^{13}$ ligamentous, ${ }^{40}$ etc. Yang et al. ${ }^{13}$ have demonstrated that neural stem cells could attach and migrate well and neurite outgrowth was supported by aligned $n$-fibers. Human ligament fibroblasts were also found to be oriented in the direction of aligned $n$-fibers, ${ }^{40}$ forming oriented bundles and significantly more collagen than that produced by cells cultured on randomly oriented fibers.

\subsection{Developed Nanomats}

So far, most of reports involved studies on developing plain $n$-scaffolds. However, recently, more functions have been added to these scaffolds by combining drug release properties to render such biomaterials multifunctional. Characteristics of $n$-scaffolds can be controlled via the functionalization of the $n$-fibers that can be achieved through one of three main methods: ${ }^{15}$

(1) mixing bioactive agents with the biodegradable polymer solutions to prepare bioactive composite $n$-fibers,

(2) surface modification of the whole nanofibrous scaffolds; or

(3) employing a coaxial $e$-spinning, to produce fibers with core-shell structure.

This new category of bioactive multifunctional scaffolds (Table II) has been developed after the convergence of drug release and scaffold processing technologies. The principle of local drug release has been developed to avoid or at least limit side effects of drugs. In many systems where implants are produced, heat-based processing systems are used to manufacture drug releasing implants, ${ }^{116-122}$ making the inclusion of heat-sensitive molecules impossible. Employing $e$-spinning has enabled researchers to develop multifunctional fibers and scaffolds that are capable of releasing drugs, ${ }^{19-26,83,86,123,124}$ polypeptides, ${ }^{27-29,123-125}$ or polyneucleotiedes, ${ }^{96,97}$ etc. It also allows for combining of more than one agent of different categories in the multifunctional construct. ${ }^{123}$ In addition, one can extert control on the release of multiple agents. This is especially important to enhance the multifunctionality and take of tissue engineering "grafts" when implanted in the body. Therefore, it is essential to develop a system, that can deliver drugs/morphogens of interest in the appropriate time, for appropriate duration and at precise location. Depending on the characteristics that a drug of interest has, there is a need for development of drug special carriers since some drugs may have low stability, poor water solubility or high toxicity. Due to their high surface area to volume ratio, and porosity, $e$-spun $n$-fiber-based nanomats are interesting materials to be used as multifunctional tissue engineering scaffolds.

During preparation of drug releasing nanomats, the drug of interest is mixed with the appropriate polymer and then the mixure is $e$-spun to obtain nanofibrous structures. However, it is not clear from the results of some cases whether added agent/drugs are included inside the fibers or lie on their surface. This is affected by drug characteristics. In contrary to other release systems, those produced with $e$-spinning can be used to include both hydrophobic and hydrophilic drugs. A polymeric carrier leads to the supression or delay of recrystallization of the drug dispersed in it, by making the drug pharmaceutically useful for the desired period of time. ${ }^{126}$ Verreck et al. ${ }^{126}$ have demonstrated the possibility of delivering poorly water soluble drugs in a controlled manner by using $e$-spun nonbiodegradable polymeric fibers. Itraconazole (antifungal drug) and ketanserin (a selective S2-serotonin antagonist for the acceleration of wound healing) were used as model drugs.

Various strategies have been studied to control the release kinetics of loaded agents from $e$-spun fibers. Drugs can covalently be conjugated to the polymer matrix as shown in some reports. ${ }^{25}$ Another method involves postelectrospinning coating of drug-loaded $n$-fibers. ${ }^{125}$ A new technique of coaxial $e$-spinning was also developed to produce fibers having a core and shell structure. The loaded agent can be included in the core and shell would function as a control mechanism over the release of the loaded agent. ${ }^{27}$ This method entails feeding of two different solutions to be spun through two concentrically arranged needles. The co-electrospinning of the two solutions leads to the formation of fibers having core and shell. The method can be beneficial for containing and controlled 
Table II. Multifunctional/bioactive electrospun nanofiber-based nanomats.

\begin{tabular}{|c|c|c|}
\hline Polymer & Combined agent & Ref. \\
\hline \multicolumn{3}{|l|}{ A. Pharmaceutical agents } \\
\hline $\begin{array}{l}\text { PLA (Medisorb }{ }^{\circledR} 100 \text { L PLA), Poly(ethylene-co-vinyl acetate) and their } \\
\text { 50:50 blend }\end{array}$ & Tetracycline hydrochloride & [19] \\
\hline Poly(DL-lactide), Poly(L-lactide) & Mefoxin & {$[20]$} \\
\hline Poly(L-lactide) & Rifampin, Paclitaxel & {$[21]$} \\
\hline Poly(lactide-co-glycolide) & Cefoxin Sodium & [22] \\
\hline Poly(lactide-co-glycolide), poly(ethylene glycol)- $b$-poly(DL-lactide) & Mefoxin $^{\circledR}$ & [23] \\
\hline Hydroxypropylmethylcellulose $\mathrm{e}^{b}$ & Itraconazole & [24] \\
\hline $\begin{array}{l}\text { Poly(lactide-co-glycolide), poly(ethylene glycol)-g-chitosan (composite } \\
\text { membrane) }\end{array}$ & Ibuprofen & {$[25]$} \\
\hline $\operatorname{Poly}(\varepsilon$-caprolactone $)$ & Heparin & [26] \\
\hline Poly( $\varepsilon$-caprolactone $)$ & Dicolfenac sodium (Voltaren) & [86] \\
\hline $\begin{array}{l}\text { Buntan-1-olo hemister of poly(maleic anhydride-alt-2-methoxyethyl } \\
\text { vinyl ether polymer) (PAM14) }\end{array}$ & Dicolfenac sodium (Voltaren) & {$[83,123,124]$} \\
\hline \multicolumn{3}{|l|}{ B. Polypeptides } \\
\hline $\begin{array}{l}\text { Shell-core system: Poly( } \varepsilon \text {-caprolactone) shell and poly(ethylene glycol) } \\
\text { core }\end{array}$ & BSA in the core & {$[27]$} \\
\hline $\begin{array}{l}\text { Shell-core system: Poly( } \varepsilon \text {-caprolactone) shell and poly(ethylene glycol) } \\
\text { core }\end{array}$ & Lysozyme in the core & [27] \\
\hline $\begin{array}{l}\text { Buntan-1-olo hemister of poly(maleic anhydride-alt-2-methoxyethyl } \\
\text { vinyl ether polymer (PAM14) }\end{array}$ & Human serum albumin & {$[123,124]$} \\
\hline Silk poly(ethylene oxide) & Bone morphogenetic protein 2 (BMP-2) & [29] \\
\hline Poly(vinyl alcohol) coated with poly $(p$-xylylene $)(\mathrm{PPX})^{a}$ & $\begin{array}{l}\text { Fluorescin isothiocyanate labeled bovine serum albumin } \\
\text { (FITC-BSA) }\end{array}$ & {$[125]$} \\
\hline Poly(vinyl alcohol) coated with poly $(p$-xylylene $)(\mathrm{PPX})^{a}$ & Luceferase & {$[125]$} \\
\hline $\operatorname{Poly}(\varepsilon$-caprolactone-co-ethyl ethylene phosphate) & $\begin{array}{l}\text { Human } \beta \text {-Nerve growth factor (NGF) in bovine serum } \\
\text { albumin }\end{array}$ & {$[28]$} \\
\hline \multicolumn{3}{|l|}{ C. Polynucleotides } \\
\hline Poly(lactide-co-glycolide), Poly(DL-lactide)-poly(ethylene glycol) & $\mathrm{pCMV} \beta$ plasmid encoding $\beta$-galactosidase & [96] \\
\hline $\begin{array}{l}\text { Poly(lactide-co-glycolide), Poly(DL-lactide)-poly(ethylene glycol)- } \\
\text { poly(DL-lactide) (for DNA encapsulation) }\end{array}$ & $\mathrm{pCMV} \beta$ plasmid encoding $\beta$-galactosidase & [97] \\
\hline \multicolumn{3}{|l|}{ D. Ceramics } \\
\hline $\operatorname{Poly}(\varepsilon$-caprolactone $)$ & $\mathrm{CaCo}_{3}$ & {$[94,136]$} \\
\hline Polyhydroxybutarate valerate- 5 & Hydroxyapatite & [129] \\
\hline Poly $(\varepsilon$-caprolactone $)$ & Hydroxyapatite & [136] \\
\hline Silk poly(ethylene oxide) & Nano-Hydroxyapatite & [29] \\
\hline \multicolumn{3}{|l|}{ E. Ceramics and polypeptides } \\
\hline Silk poly(ethylene oxide) & Nano-Hydroxyapatite /BMP-2 & [29] \\
\hline
\end{tabular}

${ }^{a}$ PPX was used for coating and it is a highly hydrophobic and very solvent resistant polymer.

${ }^{b}$ To assess the use of $e$-spinning for the difficult task of controlled delivery of a highly poorly water-soluble model drug. Water-soluble polymer, hydroxypropylmethylcellulose (HPMC) was used.

release of water-soluble molecules such as proteins, with potential use in tissue engineering. It has been emphasized that this process is easier and has a higher efficiency than traditional methods used for encapsulation of growth factors or proteins. ${ }^{27}$ Loscertales et al. ${ }^{127}$ reported on a new method to generate steady coaxial jets with diameters in the range of micro-/nano-meter size. This compound jet was generated by the action of electro-hydrodynamic forces resulting in the formation of an aerosol of monodisperse compound droplets with the inner liquid being surrounded by the outer one. Resulting capsules had a diameter of $0.15-10 \mu \mathrm{m}$. Co-electrospinning was thus employed for the development of core-shell fibers to add more versatility to the technique. ${ }^{128}$

Another study included bovine serum albumin or luciferase release from $e$-spun PVA $n$-fibers that were coated with hydrophobic poly $(p$-xylylene $) .{ }^{125}$ Significant retardation of release in the case of coated $n$-fibers was observed, and the activity of the released enzyme was maintained. This can offer a system that may be used for tailoring drug release. In our studies, human albumin was used as a release control check. ${ }^{124}$ An approach involving cross-linking of amino groups of incorporated protein, in order to slow the release of loaded agents is being explored by our groups in studies on multifunctional scaffolds. ${ }^{124}$

Zeng et al. ${ }^{125}$ have found that the release of bovine serum albumin (BSA) from poly( $p$-xylylene) (PPX)coated PVA/BSA composite can significantly be retarded due to the PPX coating even at $37^{\circ} \mathrm{C}$. This has also been found to be influenced by the thickness of the coating layer. A further slower release of BSA was observed with a PPX layer thickness of $250-300 \mathrm{~nm}$ as compared with thickness of $80-100 \mathrm{~nm}$. This effect is achieved due to the 
high hydrophobicity and solvent resistance properties of PPX. Thus, control of release for prolonged time intervals can be achieved by adapting water impermeability of the shell polymer.

Changing voltage was also found to influence the rate of release. ${ }^{24}$ For example, at $60 \mathrm{~min}, 40 \%$ release of the antifungal Itraconazole release from samples processed using $24 \mathrm{kV}$ was seen while those processed using $16 \mathrm{kV}$ released $70 \%$ of the drug. Complete release was obtained at $<160 \mathrm{~min}$ for the $16 \mathrm{kV}$ sample and at $240 \mathrm{~min}$ for the $24 \mathrm{kV}$ one. In this study, it was also demonstrated that the use of $e$-spinning is useful for addressing the difficult task of controlled delivery of a poorly water-soluble model drug from a water-soluble polymer (hydroxypropylmethylcellulose). $e$-spun samples were also found to result in a slower dissolution in vitro as compared to powders made of samples prepared by cast thin films or melt extrusion.

Zhong et al. ${ }^{114}$ have added chondroitin-6-sulfate (CS) sodium salt (from bovine trachea) to type I collagen (calf skin) and the blend was $e$-spun to $n$-scaffolds so that in addition to mimicking native tissues structurally, such biomimetic $n$-scaffolds may enhance biological interactions with cells and speed up tissue regeneration by introducing cell-specific ligands or extracellular signaling molecules and by CS interaction with serum growth factors and cytokines.

\subsection{Characterization of Nanomats}

\subsubsection{Material Properties}

Important requirements of a scaffold are biocompatibility and biodegradability so that no adverse tissue reactions occur when implanted in tissues. Furthermore, it should possess an appropriate surface chemistry and porosity to allow easy attachment of cells and also good mechanical properties to resist stresses that may occur. It is also important to define morphology and structural characteristics of the resulting scaffolds. Scanning electron microscopy (SEM) and transmission electron microscopy (TEM) are common tools that are used for the assessment of the structure of resulting nanomats and for various measurements, such as fiber diameter, bead size (length and diameter), fiber morphology, etc. ${ }^{69}$ Porosity can be measured using porosimeter. $^{41}$

Wide-angle X-ray diffraction (WAXD) is used for finding out, e.g., orientation of polymer chains and crystallization of polymer that can occur during $e$-spinning process. ${ }^{69,20}$ With differential scanning calorimetry (DSC) crystallization of $n$-fibers can also be studied. The molecular structure of $n$-fibers manufactured from blends of the two materials and their inter-molecular interactions can be determined using $\mathrm{NMR}^{20}$ and Fourier transform infra-red (FTIR). ${ }^{107}$

For mechanical properties of scaffolds, elongation-atbreak, ultimate strength and Young's modulus are obtained from the mechanical tests, which are increased by increasing fiber diameter. ${ }^{77,81,102}$ Studies should also include in vitro and in vivo evaluation of scaffolds behavior and degradation. ${ }^{81,129}$

\subsubsection{Drug Release Studies}

When dealing with multifunctional nanomats, one has to define drug or contained molecule release profiles. The follow-up of drug release from nanomats takes place, usually, by studying specimens incubated in vitro. Appropriate methods are used for the identification and calculation of the amount of released agent. In studies on the release of diclofenac sodium, ${ }^{83,86,124}$ we have employed UV-vis spectroscopy where the absorbance of drug at $276 \mathrm{~nm}$ was determined and the concentration of released drug is calculated from its extinction coefficient at given wavelength. For other molecules, appropriate methods such as complex forming and immunoassays can be used. For example, the release of human serum albumin can be evaluated by a colorimetric assay. Sample and standard absorbance at $562 \mathrm{~nm}$ can be measured by means of a spectrophotometer. ${ }^{83}$

\subsubsection{Cell Culture}

Several cell culture studies were carried out to define cellcompatibility studies, and much can be learnt from these studies to enable the development of tissue engineering constructs. These studies looked at the effect of scaffolds on cell viability, proliferation, and differentiation. Studies that aimed specifically at developing tissue engineering constructs are increasingly being published. So far, various types of cells have been used with $n$-fiber-based scaffolds including endothelial cells (ECs), ${ }^{16,30,33,35,91,112,113,130-132}$ keratinocytes, ${ }^{103}$ hepatocytes ${ }^{39}$ smooth muscle cells (SMCs), ${ }^{31,34,35,99,101,130,132-134}$ myoblasts, ${ }^{135}$ satellite cells, ${ }^{135}$ myofibroblasts, ${ }^{32}$ fibroblasts, ${ }^{41,103,115,133,136}$ ligament fibroblasts, ${ }^{40}$ conjunctiva fibroblasts, ${ }^{114}$ articular chondrocytes, ${ }^{102}$ osteoblast-like cells, ${ }^{42}$ calvarial derived osteogenic cells, ${ }^{10}$ or osteoblasts, ${ }^{137}$ pre-osteoblastic cells, ${ }^{96,97}$ osteoblasts, ${ }^{136,94}$ mesenchymal stem cells (MSCs), ${ }^{29,41,43}$ neural stem cells, ${ }^{38}$ and cerebellum stem cells. ${ }^{13}$ Most of cell-based studies involved plain polymers except for very few studies that involved drug/active molecule releasing nanoscaffolds. A study by Li et al., ${ }^{29}$ investigated multifunctional bioactive silk fibroin fiber scaffolds-based scaffolds, containing hydroxyapatite nanoparticles (nHAp) and bone morphogenetic protein 2 (BMP-2), using human bone marrow-derived MSCs. In another study, cell culture was used for the assessment of released agent bioactivity. Chew et al. ${ }^{28}$ used PC12 cells (differentiate to a neuronal phenotype in presence of human $\beta$-nerve growth factor NGF) to study the bioactivity of NGF released from $e$-spun copolymer of $\varepsilon$-caprolactone and ethyl ethylene phosphate (PCLEEP). Cells were found to differentiate into neurons indicating 
that released NGF has retained a degree of its bioactivity. NGF release from the PCLEEP fibers extended for up to 3 months, which is considered useful because NGF has a short half-life in vivo (elimination half-life of less than $5 \mathrm{~h}$ in adult rats ${ }^{138}$ ). In a study by Liang et al. ${ }^{97}$ MC3T3-E1 (pre-osteoblastic cell line) were used to evaluate the transfection efficiency of DNA delivered from PLA-PEG-PLA triblock copolymer nanoparticles incorporated in PLGA $n$-fibers. MC3T3 cells were incubated with two types of DNA loaded scaffolds (those that had block copolymer and those that had not). Those scaffolds without the block copolymer were found to contain degraded DNA (due to $e$-spinning), while DNA released from scaffolds having the block copolymer was structurally intact. Sustained release of intact DNA from PLGA scaffold was measured. After seven days, a large fraction (ca. 75\%) of the DNA remained in the partially degraded scaffold. There was no evident transfection in cells incubated with PLGA and DNA scaffolds that had no tribloc copolymer. Transfection was, on the other hand, observed with scaffolds that had the triblock copolymer. DNA complexed with the transfection reagent, Fugene, resulted in further enhancement of transfection efficiency. It was thought that control of the fabricated scaffold could be developed to lead ultimately to improved transfection efficiency.

Ito et al. ${ }^{129}$ studied PHBV $n$-fibrous film (fiber average diameter of $185 \mathrm{~nm}$ ) composited with HAp by soaking in simulated body fluid. $n$-fibrous film was hydrophobic when compared to PHBV cast (flat) film. After HAp deposition, both of the surfaces were hydrophilic. They have incubated COS-7 cells (originating from the kidney of Africa green monkey) with developed materials for $1.5 \mathrm{~h}$. There was no explanation in the study as regards to why these cells were specifically used. According to authors, ${ }^{129}$ these cells were used to study the interaction between the $n$-fibrous film and cells. $n$-fibrous film was associated with enhanced cell adhesion as compared with flat film. Cell adhesion, however, was not significantly affected by HAp. The number of adhered cells to the nanofibrous mats was significantly higher than to flat surface films. HAp composition did not significantly affect cell adhesion.

Wutticharoenmongkol et al. ${ }^{136}$ used human osteosarcoma osteoblast cell line ( $\mathrm{SaOS} 2)$ and mouse fibroblasts (L929) in cytotoxicity tests to evaluate scaffolds that were made of $e$-spun fibers of PCL, PCL containing $\mathrm{CaCO}_{3}$, or PCL containing HAp nanoparticles. As-spun neat PCL fibers had an average diameter of about $0.95 \mu \mathrm{m}$ and as-spun composite fibers had a diameter of $1.02-1.26 \mu \mathrm{m}$. All of the three scaffold types were nontoxic to both types of tested cells, suggesting that these materials can have a potential for use as bone scaffolds.

Kim et al. ${ }^{137}$ have used immortalized mouse calvarial osteoblasts (MC3T3-E1) to evaluate the cytotoxicity of $n$-scaffolds that were made by $e$-spinning of multicomponent PLA blends. Blends had PDLLA (40 wt \%), PLGA
50/50 (25 wt \%), poly(DL-lactide)-poly(ethylene glycol)poly(DL-lactide) [PDLLA- $b$-PEG- $b$-PDLLA] (20 wt $\%$ ), and lactide $(15 \mathrm{wt} \%)$. Cells were incubated in media containing either lactide or triblock copolymer at different concentrations. It was found that at higher lactide concentrations (e.g., $30 \mathrm{mg} / \mathrm{ml}$ ), cell viability decreased dramatically, especially by 2 and 3 days. On the other hand, triblock copolymer did not affect cell proliferation even at high concentrations (e.g., $30 \mathrm{mg} / \mathrm{ml}$ ). It was, thus, concluded that the incorporation of triblock copolymer at a concentration of $30 \mathrm{mg} / \mathrm{ml}$ and of lactide at a concentration of $20 \mathrm{mg} / \mathrm{ml}$ (as used in the blend in this study) is safe and it does not damage cellular growth. Authors suggested that this 4-component blend made into non-woven scaffold might be of benefit in cell delivery for bone regeneration.

In a biocompatibility test, Zhong et al. ${ }^{114}$ used rabbit conjunctiva fibroblasts to investigate in vitro biocompatibility of blended collagen and either $4 \%$ or $10 \%$ CS chondroitin-6-sulfate (CS) $n$-scaffolds, that were developed for potential use in tissue engineering. The $4 \%$ CS scaffolds were used as $18 \%$ concentration solutions while the $10 \%$ CS ones were used as $12 \%$ solutions that underwent $e$-spinning. Scaffolds were crosslinked subsequently by using glutaraldehyde (GA). The $10 \%$ CS scaffolds had lower mean fiber diameter $(180 \mathrm{~nm})$, but wider diameter distribution. The $4 \% \mathrm{CS}$ ones had a mean diameter of $260 \mathrm{~nm}$. It is worth noting that CS is a salt and this may have had an effect on conductivity, thus reducing fiber diameter. Scaffolds were tested for degradation using collagenase and it was found that cross-linked ones had significantly lower degradation rate. On day 3, noncrosslinked scaffolds had $90 \%$ of their fibers digested while crosslinked ones had only 35\% digested by 6 days. Obviously, this was also a factor responsible of increased cell proliferation that was observed to occur in crosslinked ones. This also indicates that the used GA did not have appreciable toxic effects, probably because of the procedure used after cross-linking. In addition, CS $4 \%$ scaffolds were associated with significantly higher cell proliferation at day 7, when compared to non-CS containing scaffolds. At day 7, cells exhibited typical fibroblastic morphology with flattening and polygonal extensions with fibroblast tethering to the $n$-fibers. It was concluded that these collagen CS crosslinked scaffolds have excellent biocompatibility with potential use in tissue engineering.

Kim et al. ${ }^{139}$ have used human prostate epithelial cells to test for cell attachment and proliferation on PCL $n$-scaffolds that were developed to have improved wettability by co-electrospinning with PVA. Cell attachment and proliferation was improved by including PVA which is probably due to improved scaffold hydrophilicity.

To assess cytocompatibility of silk fibroin with the aim of developing a nonwoven-type wound dressing, Min et al. ${ }^{103}$ used primary human oral keratinocytes, primary normal human epidermal keratinocytes, and primary normal human gingival fibroblasts. Silk $n$-fibers were found 
to promote cell adhesion and spreading of collagen type I. It was concluded that silk fibroin $n$-fibers are good candidates for tissue engineering.

\subsubsection{In Vivo Studies}

An in vivo study (conducted in rats) ${ }^{81}$ involved non-woven PCL nanomats that were produced by $e$-spinning. The fiber diameter significantly influenced in vivo biodegradation rates. In vivo degradation was found to be faster than in vitro. Degradation of nanomats (membranes) was slower than solvent-cast membranes, probably because they were more hydrophobic. In another study, ${ }^{140}$ PCL $n$-scaffolds that were seeded with MSCs, were implanted in rats for 4 weeks, and the constructs were found to maintain their original size and shape.

\section{TISSUE ENGINEERING}

For tissue engineering, it is important to have a biomimetic porous structure with thin fibers. In studies on osteoblasts, it was reported that adhesion, proliferation, alkaline phosphatase (AP) activity, and ECM production on carbon $n$-fibers was increased with thinner fibers having diameter in the range of 60-200 nm. ${ }^{141}$ Studying PLLA nano-/ micro-fibrous scaffolds for neural tissue engineering, Yang et al. ${ }^{13}$ found that although no significant changes in neural stem cell orientation were seen with respect to fiber diameter, the rate of cell differentiation was higher on PLLA $n$-fibers than that on microfibers.

Adding molecule release function to nanoscaffolds may advance applications further for use in controlled tissue repair. Resulting multifunctional device may enable control over tissue reactions. Moreover, the use of bioactive agent releasing $n$-fibers is a promising tool in tissue engineering where the scaffold can mimic ECM further in relation to storage and release of morphogens. This can be employed to promote cell growth, and to modulate or redirect cell functions, ${ }^{93}$ making $n$-scaffolds among promising native ECM analogs. ${ }^{16}$

Increasingly, results are being reported on the use of biodegradable polymeric $n$-fibers for tissue engineering ${ }^{37,42,91,136,142}$ including engineering of neural, ${ }^{13}$ bone, ${ }^{42,136}$ cartilage, ${ }^{142}$ skin, ${ }^{37}$ and blood vessel ${ }^{30,91,113}$ tissues. These studies evaluated cell adhesion, proliferation, gene expression, and ECM secretion. For example, $e$-spun EVOH $n$-fiber mat has also been shown to be able to support the culture of SMCs and fibroblasts. ${ }^{133}$ Human embryonic palatal mesenchymal cells, ${ }^{93}$ chondrocytes, ${ }^{92}$ and bone marrow-derived $\mathrm{MSCs}^{41}$ were cultured on PLGA or PCL $n$-fibers. The $n$-fiber structure was found to support cell attachment and proliferation. NIH 3T3 fibroblasts tended to maintain their phenotypic shape when they were cultured on poly( $p$-dioxanone-co-L-lactide)-block-poly (ethylene glycol) $n$-fibers. Growth occurred according to $n$-fiber orientation. ${ }^{143}$

\subsection{Cardiovascular Tissues}

For potential application in blood vessel tissue engineering, He et al. ${ }^{113}$ used collagen-blended P(LLA-CL) 70:30 $n$-scaffolds and human coronary artery ECs. Enhanced cell viability, attachment and spreading of cells, and preservation of EC markers were observed. Enhanced ${ }^{30}$ endothelialization of collagen-coated structures with good mechanical properties has also been seen. Human coronary artery SMCs were studied on different types of matrices (PCL, collagen-coated PCL $n$-fibers, and collagen $n$-fibers) to assess suitability for blood vessel engineering, ${ }^{31}$ were found to grow in the direction of fiber orientation. Compared to plain PCL, collagen-coated PCL fibers were associated with better cell attachment, migration, and proliferation, as well as better morphology of $\alpha$-actin filaments. EC orientation followed aligned $n$-fibers (gelatin-grafted PCL $n$-fibers) with full cell spreading by days 2 and $4,^{112}$ while cells assumed round-shape and did not spread on random $n$-fibers. Grafting of gelatin on PCL has also improved cell proliferation, compared with the poor cell growth on unmodified PCL. EC phenotype was also preserved on gelatin-modified PCL, as indicated by the expression of the important characteristic surface markers.

Comparing knitting with $e$-spinning of fibrin gel to develop materials for blood vessel engineering, ${ }^{32}$ human myofibroblasts exhibited good cell proliferation on both types of scaffolds. Although it was poorer in $e$-spun ones, no significant difference in collagen production on both scaffold types was found. Higher seeding efficiency was seen in $e$-spun scaffolds.

Mo et al. ${ }^{130}$ looked at the cell behaviour of SMCs and ECs on nanofibrous P(LLA-CL) 75:25 scaffolds. Compared to day 1, there was an increase in cell density of both cell types at day 3 . The cells were also observed to migrate and proliferate and form a continuous monolayer. At day 7 , cells, especially SMCs, increased significantly in number and almost reached confluence. Xu et al. ${ }^{33}$ looked at function of human vascular ECs on substrates with different surface roughness (in vitro). They have compared $e$-spun PLLA $n$-scaffolds to solvent cast produced smooth surface films. ECs showed enhanced function on smooth films as compared to rough surface fibers. In another study, ${ }^{91}$ human umbilical vein ECs were shown to adhere, spread and proliferate better on surfaces with high-density fabrics and especially on fibers with smaller diameter $(0.3$ and $1.2 \mu \mathrm{m})$. On large-diameter-fiber fabrics $(7.0 \mu \mathrm{m})$, cell adhesion was markedly reduced, cell spreading was restricted and there were no signs of proliferation. ${ }^{91}$ The scaffolds with large diameter fibers had also many largesize pores with cells adhered on single fibers, were round in shape and with non-proliferating cells predominating. Such behavior is probably the result of large interfiber distance or a very low surface density of fibers, which did not permit cell adhesion across the neighboring fibers. ${ }^{91}$ 
The study, does however, demonstrate potential for application of $n$-scaffolds in vascular tissue engineering. Xu et al. ${ }^{132}$ have also looked at human coronary artery SMCs and ECs on P(LLA-CL) 75:25 $e$-spun substrates to check the suitability of such scaffolds for engineering blood vessels. Although both cell types attached and proliferated well on the scaffolds, the rate was higher for SMCs than for ECs. However, as time increased, proliferation rate became slower. Both cell types expressed specific phenotypes and favorable interactions between SMCs and ECs on the scaffold were demonstrated.

Stankus et al. ${ }^{34}$ investigated rat aortic SMCs microintegration into poly(ester urethane)urea (PEUU) $e$-spun scaffolds. No significant change in SMC number was seen in static cultures (at 1, 4, and 7 days) while higher cellular density was seen in perfusion cultures. Improved physical properties of scaffolds was achieved by the addition of PLGA to a mixture of collagen type I (from half skin), elastin (from ligamentum nuchae) and PLGA $(45: 40: 15){ }^{35}$ Good biocompatibility of the scaffolds with bovine ECs and SMCs was observed of scaffolds, making these scaffolds potential candidates for development of vascular grafts. $n$-fiber-based meshes made by $e$-spinning of a blend of collagen type I and elastin in various ratios. ${ }^{134}$ Fibers had diameters ranging from 220 to $600 \mathrm{~nm}$. Increased elastin content led to increased fiber diameter. To render them stable, scaffolds were subsequently cross-linked, using $N$-(3-dimethylaminopropyl)$N^{\prime}$-ethylcarbodiimide hydrochloride (EDC), in the presence of $N$-hydroxysuccinimide (NHS), to avoid glutaraldehyde cytotoxicity. ${ }^{144}$ SMCs have reached confluence on the scaffolds by day 14 of culture.

Zong et al. ${ }^{36}$ investigated the suitability of PLGA 10/90, PLGA 75/25, semi-crystalline PLLA, and PEGPDLLA diblock copolymeric $e$-spun scaffolds for culture of primary cardiomyocytes and development of engineered heart tissue. Post-processing was applied to $e$-spun scaffolds to achieve macro-scale fiber orientation (anisotropy). Fine fiber architecture of the non-woven matrix allowed cardiomyocytes to crawl inside and pull on fibers. Cardiomyocytes on $e$-spun PLLA scaffolds developed mature contractile machinery (sarcomeres). Functionality (excitability) of the engineered constructs was also confirmed. It was concluded that engineered cardiac tissue structure and function can be modulated by the chemistry and geometry of the provided nano- and micro-textured surfaces.

Li et al $^{93}$ studied human embryonic palatal mesenchymal cells cultured on collagen, gelatin (denatured collagen), solubilized $\alpha$-elastin, and recombinant human tropoelastin $n$-scaffolds. On day 2, cell growth on all of the scaffolds was consistently equal to or (for elastin) slightly higher than that on the standard tissue culturetreated polystyrene (TCPS) controls. By day 6 , there were significantly more cells on all the scaffolds than on TCPS. It was worth noting that cells grew not only on top of the scaffolds but also into them. Cells that grew at low densities on the scaffolds were found to elaborate a large number of pseudopodia, with which they have attached to individual fibers. Cells attached, spread, migrated, and proliferated to confluence equally well on collagenous as on $\alpha$-elastin and tropoelastin scaffolds. According to authors, ${ }^{93}$ these results warrant further investigations on the use of these matrices, especially the elastin and tropoelastin ones, for engineering, e.g., of cardiovascular and pulmonary tissues.

\subsection{Skin and Mucosal Tissue}

Zhang et al. ${ }^{115}$ reported on the use of human dermal fibroblast culture and collagen-coated PCL $n$-fibers. They have evaluated two types of such fibers, of which one type was produced by using coaxial $e$-spinning to have collagencoated individual fibers. The other technique produced only roughly collagen-coated PCL nanofibrous matrices, by soaking PCL matrix in collagen. Matrices that had individual fiber coatings, were associated with definitely favored cells proliferation. Cell density on these membranes increased almost linearly over 6 days of culture, but to a lesser extent on roughly collagen-coated PCL. Individual fiber coating was also associated with encouraged cell migration inside the scaffolds. Although the primary objective of this study was to compare the two types of the material and not tissue engineering, gained results may help to employ this further in tissue engineering using dermal fibroblasts.

\subsection{Neural Tissue}

Yang et al. ${ }^{13}$ explored the efficacy of aligned PLLA nano/micro $e$-spun fibrous scaffolds that for neural tissue engineering. Neonatal mouse cerebellum C17.2 stem cells were cultured with the scaffolds and they were found to elongate and have neurite outgrowth parallel to the direction of aligned fibers. No significant relation to fiber diameter was seen. The rate of cell differentiation was higher with $n$-fibers than with microfibers, irrespective of fiber alignment. Aligned nanofibrous PLLA scaffolds can, thus, have potential in neural tissue engineering. Scaffolds developed by Yang et al. ${ }^{38}$ had an average fiber diameter of $272 \mathrm{~nm}$, median pore diameter of $21 \mu \mathrm{m}$ and surface roughness of $172 \mathrm{~nm}$. Majority of pores had a diameter of $10 \mu \mathrm{m}$, which is sufficient for nutrient exchange, yet can prevent glial scar formation. This may help to achieve successful neural tissue regeneration. When cells were cultured on these scaffolds, $61.4 \%$ of the cells have adhered to the scaffolds by $2 \mathrm{~h}$, and $70 \%$ differentiated by 1 day as indicated by exhibiting spindle-like shape with extended processes. Although cell adhesion was improved on $e$-spun PLLA as compared to smooth-surface PLLA films (surface roughness of $1 \mathrm{~nm}$ ), PLLA is a hydrophobic material that does not favour cell attachment. Because cell adhesion is a 
critical step that precedes all other steps of spreading and differentiation, it was thought that effective physicochemical modification of the surface is necessary to improve the efficiency of these scaffolds. This scaffold may have potential in neural tissue engineering.

\subsection{Hepatic Tissue}

Chua et al. ${ }^{39}$ found that fibrous poly $(\varepsilon$-caprolactone-coethyl ethylene phosphate) scaffolds (average fiber diameter of $760 \mathrm{~nm}$ ) that were covalently conjugated with galactose ligands led to better rat hepatocyte aggregate formation and cell function and scaffold aggregate integration as compared with scaffolds that had no ligands. Cell aggregates have embraced $n$-fibers of the scaffolds. The study demonstrated that biochemical cues may be more important than topographical cues in terms of function. Potentially, these scaffolds may have application in hepatic tissue engineering.

\subsection{Muscle}

Riboldi et al. ${ }^{135}$ have developed $e$-spun $n$-scaffolds from biodegradable DegraPol ${ }^{\circledR}$ (Table I). The scaffolds had a thickness of about $100 \mu \mathrm{m}$, fiber diameter of ca. $10 \mu \mathrm{m}$ and a fiber-to-fiber distance of ca. $10 \mu \mathrm{m}$ with slight preferential fiber orientation. The scaffolds had a tensile strength of $2.52 \pm 0.17 \mathrm{MPa}$ and elongation at break of $220.40 \pm 57.9 \%$. Because of the limitations of current tissue engineering technologies that employ other scaffolds, and thus making clinical application unrealistic, this $n$-scaffold was developed as a valid alternative. Using murine myoblast cell line ( $\mathrm{C} 2 \mathrm{C} 12)$, rat myoblast cell line (L6), and primary human satellite cells (HSCs), were studied for cell viability, adhesion and differentiation on coated (with the proteins, Matrigel, fibronectin, or collagen) and uncoated DegraPol ${ }^{\circledR}$ slides. The study demonstrated the absence of toxic residuals and satisfactory mechanical properties. Both cell lines and HSCs adhered, proliferated and fused on coated scaffolds. C2C12 myotubes tended to align along the preferential direction of the fibers. Differentiation of $\mathrm{C} 2 \mathrm{C} 12$ to multinucleated cells has occurred as indicated by positive staining for myosin heavy chain.

\subsection{Ligament/Tendon}

Because a $n$-fiber matrix alone would not sufficiently be strong for engineering fibrous connective tissues such as tendon and ligament, it was thought that a combination of $e$-spun $n$-fibers to knitted scaffold could be more advantageous. Sahoo et al. ${ }^{98}$ have thus developed a scaffold that comprised PLGA $n$-fibers $e$-spun onto the surfaces of a knitted PLGA scaffold, to combine favored properties (mechanical strength and integrity) of knitted microfibers to those of $n$-fibers (large surface area and the better hydrophilicity), with improved cell attachment,
ECM deposition and tissue formation. Porcine bone marrow stromal cells were seeded onto these scaffolds and also on control knitted PLGA scaffolds. It was found that cell attachment was comparable in both test groups while cell proliferation was faster in the new combination scaffold. Cell function was more active in the combination scaffold test group as could be indicated by the higher expression of genes encoding for collagen I, decorin, and biglycan.

\subsection{Cartilage}

Li et al. ${ }^{41}$ used human bone marrow-derived MSCs to assess cell proliferation and mouse fibroblasts to assess cell interaction with $e$-spun PLGA scaffolds. The scaffolds had a fiber diameter of $500-800 \mathrm{~nm}$, porosity of $91.63 \%$ and pore diameter of 2-465 $\mu \mathrm{m}$ (majority 25 $100 \mu \mathrm{m})$. Cell numbers in the scaffold increased reaching a plateau by day 7, and having 5-fold increase by day 10 . Fibroblasts adhered, spread, and migrate under layers of the scaffold already by day 3 following the direction of fibers and integrating with them. In addition, the scaffold had good mechanical properties making it suitable for engineering tissues such as cartilage. Shields et al. ${ }^{102}$ have developed and investigated collagen type II (from chicken sternae) $n$-scaffolds (either cross linked or noncrosslinked). They have used immortalized cell line of adult human articular chondrocytes (T/C 28a2) cultures to look at cell attachment, distribution and proliferation after 7 days in cultures. Average thickness of crosslinked scaffolds was $0.52 \pm 0.07 \mathrm{~mm}$ and that of non-crosslinked ones was $0.20 \pm 0.02 \mathrm{~mm}$. Average fiber diameter in crosslinked scaffolds was $1.46 \mu \mathrm{m}$ and that of fibers in non-crosslinked ones was $496 \mathrm{~nm}$. Non-crosslinked scaffolds had an average pore area of $6.94 \mu \mathrm{m}^{2}$. Non-crosslinked scaffolds had an average tangent modulus of $172.5 \pm 36.1 \mathrm{MPa}$, ultimate tensile strength of $3.3 \pm 0.3 \mathrm{MPa}$, and ultimate strain of $0.026 \pm 0.005 \mathrm{~mm} / \mathrm{mm}$. Seeded cross-linked scaffolds were associated with adherence, proliferation, and infiltration of chondrocytes, including the formation of pseudopodia. Further investigation using additional biochemical and immunohistochemical methods was suggested for determining maintenance of the chondrocyte phenotype and the products of ECM synthesis. It is worth noting that the thickness of human articular cartilage is approximately $1.5 \mathrm{~mm}$. It is thus important to fabricate thicker $e$-spun scaffolds to withstand manipulation for in vivo testing. $e$-spun scaffolds can have tailored fiber and pore diameter, fiber orientation, and ultimately specific mechanical properties, which is an advantage.

Chondrocytic phenotype was evaluated by reverse transcription-polymerase chain reaction (RT-PCR). Chondrocytes seeded on PCL $n$-scaffolds and cultured in serumfree medium were found to continuously maintain their phenotype as indicated by the expression of cartilagespecific ECM genes. PCL $n$-fibers were also found to promote chondrocyte proliferation when serum-containing 
cultures were used. $^{92}$ Adult bone marrow-derived MSCs cultured in a PCL $n$-scaffolds were induced to differentiate into chondrocytes in the presence of transforming growth factor $\beta 1$ (TGF- $\beta 1$ ), as indicated by the expression of chondrocyte-specific genes and the synthesis of cartilageassociated ECM proteins. ${ }^{93}$

\subsection{Bone}

For bone tissue engineering, Tuzlakoglu et al. ${ }^{42}$ have shown the potential of starch/PCL (30:70\%)-based scaffolds. A combination of nano- and micro-fibers, obtained by $e$-spinning and fiber bonding techniques, was used as a 3D scaffold and it has been concluded that this kind of cell carrier has a higher ability to enhance cell (human osteoblast-like osteosarcoma SaOs-2 cell line and rat bone marrow stromal cells) attachment and organization and a higher AP activity as well, when compared to carriers without $n$-fibers.

Yoshimoto et al. ${ }^{43}$ have seeded PCL $n$-scaffolds with neonatal rat bone marrow-derived MSCs. Cell-polymer dynamic culture contained osteogenic supplements and was continued for 4 weeks. Cell-polymer constructs maintained the size and shape of the original scaffolds. Scaffolds were penetrated by cells and abundant ECM was seen after 1 week in culture. The surfaces of the constructs were covered with cell multilayers, mineralization and type I collagen were observed at 4 weeks of culture, suggesting that $e$-spun PCL is a potential scaffold for engineering of bone.

$\mathrm{Li}$ et al. ${ }^{29}$ studied multifunctional bioactive silk fibroin fiber scaffolds-based scaffolds. They have combined these scaffolds either with BMP-2, nanoparticles of hydroxyapatite (nHAp), or both. They have seeded them with human bone marrow-derived MSCs, for 31 days in osteogenic media. It seems that BMP-2 has survived the aqueous-based $e$-spinning process and retained its bioactivity, as the scaffolds containing BMP2 were associated with higher calcium deposition and enhanced transcript levels of bone-specific markers than in controls. Silk fibroin scaffolds supported MSC growth and osteogenic differentiation. Apatite formed on the silk fibroin/BMP-2 scaffolds had higher crystallinity than on the silk fibroin control scaffolds. nHAp particles were associated with improved bone formation. Combined BMP-2 and nHAp silk fibroin scaffolds resulted in the highest calcium deposition and upregulation of BMP-2 making them potential candidates for engineering of bone tissue engineering and systems for delivery of labile components.

Fujihara et al. ${ }^{94}$ developed two types of PCL $n$-fiber $\mathrm{CaCO}_{3}$ nanoparticle composite membranes having a PCL to $\mathrm{CaCO}_{3}$ ratio of either $75: 25$ or $25: 75$. They have cultured human osteoblasts on these scaffolds and observed good cell attachment and proliferation. No significant difference between the two types of membranes was found Authors ${ }^{94}$ suggested that further studies on osteoblast functions, such as secretion of osteonectin and osteocalcin, and alkaline phosphatase activity should be conducted for further understanding of osteoblast behaviors on these composite $n$-fiber membranes. The scaffolds have a potential use in guided bone regeneration.

Badami et al. ${ }^{10}$ investigated MC3T3-E1 (mouse calvaria-derived osteoprogenitor cell line) for the effect of different chemical and topographical features on cell adhesion, morphology, orientation, proliferation, and osteoblastic differentiation. They have used either films (spin-coated

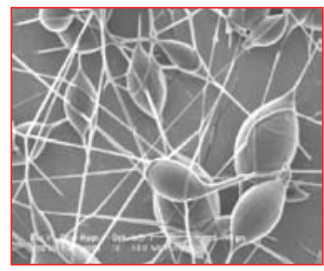

(A)

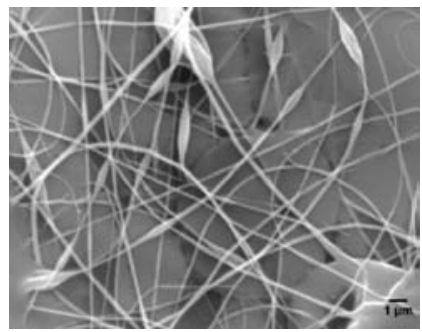

(D) PAM 5\%

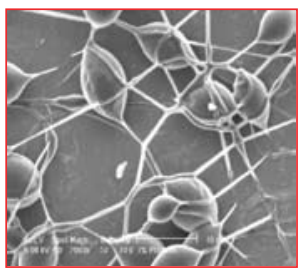

(B)

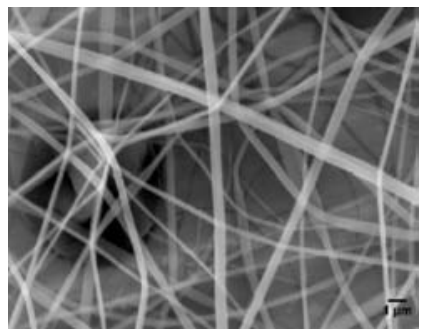

(E) PAM $8 \%$

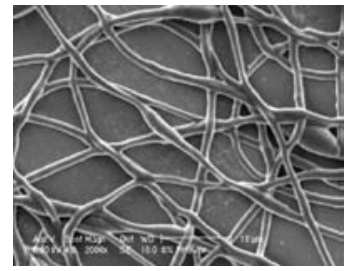

(C)

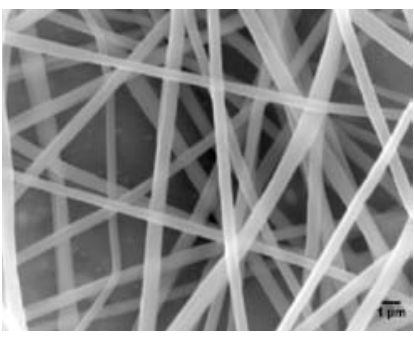

(F) PAM $10 \%$

Fig. 4. Effect of polymer solution concentration on fiber diameter and bead structure when PHBV-8 polymer was used (A) 5\%, (B) 7\%, (C) $8 \%$ concentration $(\mathrm{w} / \mathrm{v})$. Note that with increasing polymer concentration, fiber diameter increases. Similar observations can also be made with using PAM14 polymer in concentrations of 5\% (D), $8 \%(\mathrm{E})$, or $10 \%(\mathrm{~F})$. Note increasing fiber diameter and reduced number of beads (Original magnification $\times 5000$ ). 
glass) or $e$-spun scaffolds of copolymers PDLLA and PLLA, and block copolymers PEG-PDLLA and PEGPLLA (mean fiber diameters $0.14 \mathrm{~nm}$ to $2.1 \mu \mathrm{m}$ ). They have found that proliferation was increased during the 14-days culture period on all types of tested surfaces. In the absence of osteogenic factors, cell density was less on fibers than on the smooth surfaces. On the other hand, in the presence of osteogenic factors cell density on fibers was equal to or greater than that on smooth surfaces. In both cases cell density increased with increasing fiber diameter. There was no detection of ALP in the absence of osteogenic factors implying that ALP activity was unaffected by fiber topography. However, authors suggested that future work should involve determining the effects of fiber diameter on these other phenotypic markers such as the synthesis of osteocalcin and collagen, and the deposition of a calcium-phosphate. PCL $n$-scaffolds seeded with MSCs and implanted in rats for 4 weeks were found to be rigid and have a bone-like appearance with cells and formed ECM were seen throughout the constructs. ${ }^{140}$

\section{FUTURE PROSPECTS}

Polymeric nanofiber-based scaffolds have a potential wide range of potential applications in tissue repair and regeneration. Their use in tissue engineering is increasing rapidly and the potential of a variety of polymers as scaffold candidates in mimicking the ECM has been demonstrated. However, employing drug and morphogen release properties will confer extra properties on multifunctional scaffolds and mimic further native ECM. Thus, the convergence of tissue engineering, nanotechnology and drug release technologies is expected to address more of current challenges in the success and functionality of engineered grafts for regenerative medicine. To realize this, a multidisciplinary approach is needed and the development of new processing methods is essential. With appropriate funds, advances made by such convergence of research fields will have impact on science, therapy, industry, and ultimately economy.

Acknowledgments: This work is within the framework of the European Commission Network of Excellence on bone and cartilage tissue engineering "EXPERTISSUES" (Project NMP3-CT-2004-500283). Thanks are due to Ms. Hilkka Losoi for administrative assistance.

\section{References and Notes}

1. A. Ashraf and M. A. El-Hamid, Composites Part A (2005), in press.

2. X. Fu, H. Matsuyama, M. Teramoto, and H. Nagai, Sep. Purif. Technol. 45, 200 (2005).

3. H. Y. Kweon, M. K. Yoo, I. K. Park, T. H. Kim, H. C. Lee, H.-S. Lee, J.-S. Oh, T. Akaike, and C.-S. Cho, Biomaterials 24, 801 (2003).

4. H. Lu, L. Zhang, W. Xing, H. Wang, and N. Xu, Mater. Chem. Phys. 94, 322 (2005).
5. M. R. Williamson and A. G. Coombes, Biomaterials 25, 459 (2004).

6. N. Ashammakhi, J. Craniofac. Surg. 17, 3 (2006)

7. P. X. Ma and R. Y. Zhang, J. Biomed. Mater. Res. 46, 60 (1999).

8. M. S. Widmer, P. K. Gupta, L. Lu, R. K. Meszlenyi, G. R. Evans, K. Brandt, T. Savel, A. Gurlek, C. W. Patrick, Jr., and A. G. Mikos, Biomaterials 19, 1945 (1998).

9. J. D. Hartgerink, E. Beniash, and S. I. Stupp, Proc. Natl. Acad. Sci. USA 99, 5133 (2002)

10. A. S. Badami, M. R. Kreke, M. S. Thompson, J. S. Riffle, and A. S. Goldstein, Biomaterials 27, 596 (2006).

11. N. Bhattarai, D. Edmondson, O. Veiseh, F. A. Matsen, and M. Zhang, Biomaterials 26, 6176 (2005).

12. J. S. Choi, S. W. Lee, L. Jeong, S.-H. Bae, B. C. Min, J. H. Youk, and W. H. Park, Int. J. Biol. Macromol. 34, 249 (2004).

13. F. Yang, R. Murugan, S. Wang, and S. Ramakrishna, Biomaterials 26, 2603 (2005).

14. Y. Zhang, C. T. Lim, S. Ramakrishna, and Z. M. Huang, J. Mater Sci. Mater. Med. 16, 933 (2005).

15. T. Ruotsalainen, J. Turku, P. Heikkilä, J. Ruokolainen, A. Nykänen, T. Laitinen, M. Torkkeli, R. Serimaa, G. ten Brinke, A. Harlin, and O. Ikkala, Adv. Mater. 17, 1048 (2005).

16. Z. Ma, M. Kotaki, R. Inai, and S. Ramakrishna, Tissue Eng. 11, 101 (2005).

17. K. Jayaraman, M. Kotaki, Y. Z. Zhang, X. M. Mo, and S. Ramakrishna, J. Nanosci. Nanotechnol. 4, 52 (2004).

18. D. Li and Y. Xia, Adv. Mater. 16, 1151 (2004).

19. R. El Kenawy, G. L. Bowlin, K. Mansfield, J. Layman, D. G. Simpson, E. H. Sanders, and G. E. Wnek, J. Control. Release 81, 57 (2002).

20. X. Zong, K. Kim, D. Fang, S. Ran, B. S. Hsiao, and B. Chu, Polymer 43, 4403 (2002).

21. J. Zeng, X. Xu, X. Chen, Q. Liang, X. Bian, L. Yang, and X. Jing, J. Control. Release 92, 227 (2003).

22. X. Zong, S. Li, E. Chen, B. Garlick, K. Kim, D. Fang, J. Chiu, T. Zimmerman, C. Brathwaite, B. Hsiao, and B. Chu, Ann. Surg. 240, 910 (2004).

23. K. Kim, Y. K. Luu, C. Chang, D. Fang, B. S. Hsiao, B. Chu, and M. Hadjiargyrou, J. Control. Release 98, 47 (2004).

24. G. Verreck, I. Chun, J. Peeters, J. Rosenblatt, and M. E. Brewster, Pharm. Res. 20, 810 (2003).

25. H. Jiang, D. Fang, B. Hsiao, B. Chu, and W. Chen, J. Biomater. Sci. Polym. Ed. 15, 279 (2004).

26. E. Luong-Van, L. Grondahl, K. N. Chua, K. W. Leong, V. Nurcombe, and S. M. Cool, Biomaterials 27, 2042 (2006).

27. H. Jiang, Y. Hu, Y. Li, P. Zhao, K. Zhu, and W. Chen, J. Control. Release 108, 237 (2005).

28. S. Y. Chew, J. Wen, E. K. Yim, and K. W. Leong, Biomacromolecules 6, 2017 (2005)

29. C. Li, C. Vepari, H. J. Jin, H. J. Kim, and D. L. Kaplan, Biomaterials 27,3115 (2006)

30. W. He, Z. W. Ma, T. Yong, W. E. Teo, and S. Ramakrishna, Biomaterials 26, 7606 (2005).

31. J. Venugopal, L. L. Ma, T. Yong, and S. Ramakrishna, Cell Biol. Int. 29, 861 (2005).

32. M. I. van Lieshout, C. M. Vaz, M. C. Rutten, G. W. Peters, and F. P. Baaijens, J. Biomater. Sci. Polym. Ed. 17, 77 (2006).

33. C. Xu, F. Yang, S. Wang, and S. Ramakrishna, J. Biomed. Mater. Res. 71A, 154 (2004).

34. J. J. Stankus, J. Guan, K. Fujimoto, and W. R. Wagner, Biomaterials 27, 735 (2006).

35. J. Stitzel, J. Liu, S. J. Lee, M. Komura, J. Berry, S. Soker, G. Lim, M. V. Lyke, R. Czerw, J. J. Yoo, and A. Atala, Biomaterials 27, 1088 (2006)

36. X. Zong, H. Bien, C. Y. Chung, L. Yin, D. Fangm, B. S. Hsiao, B. Chu, and E. Entcheva, Biomaterials 26, 5330 (2005). 
37. T. Sun, S. Mai, D. Norton, J. W. Hayrock, A. J. Ryan, and S. MacNeil, Tissue Eng. 11, 1023 (2005).

38. F. Yang, C. Y. Xu, M. Kotaki, and S. Ramakrishna, J. Biomater. Sci. Polymer. Ed. 15, 1483 (2004).

39. K. N. Chua, W. S. Lim, P. Zhang, H. Lu, J. Wen, S. Ramakrishna, K. W. Leongm, and H. Q. Mao, Biomaterials 26, 2537 (2005).

40. C. H. Lee, H. J. Shin, I. H. Cho, Y. M. Kang, I. A. Kim, K. D. Park, and J. W. Shin, Biomaterials 26, 1261 (2005).

41. W.-J. Li, C. T. Laurencin, E. J. Caterson, R. S. Tuan, and F. K. Ko, J. Biomed. Mater. Res. 60, 613 (2002).

42. K. Tuzlakoglu, N. Bolgen, A. J. Salgado, and M. E. Gomes, J. Mater. Sci. Mater. Med. 16, 1099 (2005).

43. H. Yoshimoto, Y. M. Shin, H. Terai, and J. P. Vacanti, Biomaterials 24, 2077 (2003)

44. L. Yarin, S. Koombhongse, and D. H. Reneker, J. Appl. Phys. 90, 4836 (2001).

45. G. I. Taylor, Proc. R. Soc. London Series A 313, 453 (1969). Cited by Z. M. Huang, Y. Z. Zhang, M. Kotaki, and S. Ramakrishna, in: Compos. Sci. Technol. 63, 2223 (2003).

46. H. Fong and D. H. Reneker, Electrospinning and the formation of nanofibers, edited by David R. Salem and Martin V. Sussman, Structure Formation in Polymeric Fibers, Hanser Gardner Publications, NY (2001), p. 10.

47. J. M. Deitzel, J. D. Kleinmeyer, J. K. Hiervonen, and N. C. Beck Tan, Polymer 42, 8163 (2001).

48. D. H. Reneker, A. L. Yarin, H. Fing, and S. Koombhongse, J. Appl. Phys. 87, 4531 (2000).

49. Y. M. Shin, M. M. Hohman, M. P. Brenner, and G. C. Rutledge, Appl. Phys. Lett. 78, 1149 (2001).

50. J. Doshi and D. H. Reneker, J. Electrostatics 35, 151 (1995).

51. Z. M. Huang, Y. Z. Zhang, M. Kotaki, and S. Ramakrishna, Compos. Sci. Technol. 63, 2223 (2003).

52. D. H. Reneker, W. Kataphinan, A. Theron, E. Zussman, and A. L. Yarin, Polymer 43, 6785 (2002).

53. A. F. Spivak and Y. A. Dzenis, Appl. Phys. Lett. 73, 3067 (1998).

54. A. F. Spivak, Y. A. Dzenis, and D. H. Reneker, Mech. Res. Commun. 27, 37 (2000).

55. D. H. Reneker. in The Fourth Foresight Conference on Molecular Nanotechnology, Palo Alto, California (1997).

56. D. Reneker and I Chun, Nanotechnology 7, 216 (1996).

57. A. Formalas, US Patent, $2,323,025$ (1943).

58. A. Formalas, US Patent, $2,349,950$ (1944).

59. A. Formhals, US Patent, $1,975,504$ (1934).

60. A. Formhals, US Patent, $2,160,962$ (1939).

61. A. Formhals, US Patent, $2,187,306$ (1940).

62. Bose GM, Recheres sur la cause et sur la veritable theorie del'electicite, Wittenberg (1745). Cited by D. Reneker and I Chun, in: Nanotechnology 7, 216 (1996).

63. L. Rayleigh, Proc. R. Soc. London 14, 184 (1882).

64. J. Zeleney, Phys. Rev. 10, 1 (1917). Cited by D. Reneker and I. Chun, in: Nanotechnology 7, 216 (1996).

65. B. Vonnegut and R. L. Neubauer, J. Col. Sci. 7, 616 (1952). Cited by Z. M. Huang, Y. Z. Zhang, M. Kotaki, and S. Ramakrishna, in: Compos. Sci. Technol. 63, 2223 (2003).

66. G. I. Taylor, Proc. R. Soc. London Ser. A 280, 383 (1964). Cited by Z. M. Huang, Y. Z. Zhang, M. Kotaki, and S. Ramakrishna, Compos. Sci. Technol. 63, 2223 (2003).

67. I. Hayati, A. I. Bailey, and T. F. Tadros, J. Colloid Interf. Sci. 117, 205 (1987).

68. J. M. Dietzel, J. Kleinmeyer, D. Harris, and N. C. Beck Tan, Polymer 42, 261 (2001).

69. T. Subbiah, G. S. Bhat, R. W. Tock, S. Parameswaran, and S. S. Ramkumar, J. Appl. Polym. Sci. 96, 557 (2005).

70. J. Kameoka, R. Orth, Y. Yang, D. Czaplewski, R. Mathers, G. W. Coates, and H. G. Craighead, Nanotechnology 14, 1124 (2003).

71. A. Bornat, US Patent, 4,323,525 (1982).
72. D. Li, Y. Wang, and Y. Xia, Adv. Mater. 16, 361 (2004).

73. C. J. Buchko, L. C. Chen, Y. Shen, and D. C. Martin, Polymer 40, 7397 (1999).

74. M. M. Hohman, M. Shin, G, Rutledge, and M. P. Brenner, Phys. Fluids 13, 2201 (2001).

75. Polymer Physics, Chapter 7. http://www.eng.uc.edu/ gbeaucag/ Classes/Physics/DynChapter7html/Chapter7.html Accessed on March 11, (2006).

76. U. Boudriot, R. Dersch, A. Greiner, and J. H. Wendorff, in Proc. Nanotechnol. Sci., Economy, Soc. Marburg, Germany (2005).

77. K. H. Lee, H. Y. Kim, Y. M. La, D. R. Lee, and N. H. Sung, J. Polym. Sci. Polym. Phys. 40, 2259 (2002).

78. S. Megelski, J. S. Stephens, D. B. Chase, and J. F. Rabolt, Macromolecules 35, 8456 (2002).

79. M. G. McKee, Ph.D. Dissertation, Faculty of the Virginia Polytechnic Institute and State University, Blacksburg, Virginia, USA (2005).

80. D. S. Katti, K. W. Robinson, F. K. Ko, and C. T. Laurencin, J. Biomed. Mater. Res. 70B, 286 (2004).

81. N. Bolgen, Y. Z. Menceloglu, K. Acatay, I. Vargel, and E. Piskin, J. Biomater. Sci. Polym. Ed. 16, 1537 (2005).

82. A. Ndreu, L. Nikkola, V. Hasirci, and N. Ashammakhi, in "2nd International Conference Strategies in Tissue Engineering" organized by WITE e.V. (Würzburger Initiative Tissue Engineering), the NIH and Harvard Medical School, Würzburg, Germany (2006).

83. A. Piras, L. Nikkola, F. Chiellini, E. Chiellini, and N. Ashammakhi, J. Nanosci. Nanotechnol. (2006), submitted.

84. L. Chun, C. Ping, L. Jiafeng, and Z. Yujun, Polymer 47, 915 (2006).

85. H. Fong, I. Chun, and D. H. Reneker, Polymer 40, 4585 (1999).

86. L. Nikkola, J. Seppälä, A. Harlin, A. Ndreu, and N. Ashammakhi, J. Nanosci. Nanotechnol. (2006), accepted.

87. A. L. Yarin, S. Koombhongse, and D. H. Reneker, J. Appl. Phys. 89, 3018 (2001).

88. M. M. Demir, I. Yilgor, E. Yilgor, and B. Erman, Polymer 43, 3303 (2002).

89. C. L. Casper, J. S. Stephens, N. G. Tassi, B. D. Chase, and J. F. Rabolt, Macromolecules 37, 573 (2004).

90. J. Zeng, X. Chen, X. Xu, Q. Liang, X. Bian, L. Yang, and X. Jing, J. Appl. Polym. Sci. 89, 1085 (2003).

91. K. Kwon, S. Kidoaki, and T. Matsuda, Biomaterials 26, 3929 (2006).

92. W. J. Li, K. G. Danielson, P. G. Alexander, and R. S. Tuan, J. Biomed. Mater. Res. 67A, 1105 (2003).

93. M. Li, M. J. Mondrinos, M. R. Gandhi, F. K. Ko, A. S. Weiss, and P. I. Lelkes, Biomaterials 26, 5999 (2005).

94. K. Fujihara, M. Kotaki, and S. Ramakrishna, Biomaterials 26, 4139 (2005).

95. M.-S. Khil, S. R. Bhattarai, H.-Y. Kim, S.-Z. Kim, and K.-H. Lee, J. Biomed. Mater. Res. 72B, 117 (2005).

96. Y. K. Luu, K. Kim, B. S. Hsiao, B. Chu, and M. Hadjiargyrou, J. Controll. Release 89, 341 (2003).

97. D. Liang, Y. K. Luu, K. Kim, B. S. Hsiao, M. Hadjiargyrou, and B. Chu, Nucleic Acids Res. 33, e170 (2005).

98. S. Sahoo, H. Ouyang, J. C. Goh, T. E. Tay, and S. L. Toh, Tissue Eng. 12, 91 (2006).

99. C. Y. Xu, R. Inai, M. Kotaki, and S. Ramakrishna, Biomaterials 25, 877 (2004).

100. L. Huang, K. Nagapudi, R. P. Apkarian, and E. L. Chaikof, J. Biomater. Sci. Polym. Ed. 12, 979 (2001).

101. J. A. Matthews, G. E. Wnek, D. G. Simpson, and G. L. Bowlin, Biomacromolecules 3, 232 (2002).

102. K. J. Shields, M. J. Beckman, G. L. Bowlin, and J. S. Wayne, Tissue Eng. 10, 1510 (2004).

103. B.-M. Min, G. Lee, S. H. Kim, Y. S. Nam, T. S. Lee, and W. H. Park, Biomaterials 25, 1289 (2004).

104. H. J. Jin, S. V. Fridrikh, G. C. Rutledge, and D. L. Kaplan, Biomacromolecules 3, 1233 (2002). 
105. H. J. Jin, J. Chen, V. Karageorgiou, G. H. Altman, and D. L. Kaplan, Biomaterials 25, 1039 (2004).

106. E. D. Boland, J. A. Matthews, K. J. Pawlowski, D. G. Simpson, G. E. Wnek, and G. L. Bowlin, Front. Biosci. 9, 1422 (2004).

107. L. Huang, R. A. McMillan, R. P. Apkarian, B. Pourdeyhimi, V. P. Conticello, and E. L. Chaikof, Macromolecules 33, 2989 (2000).

108. T. Sindelar, L. Nikkola, N. Ashammakhi, M. van Griensven, and H. Redl, in 2nd International Conference "Strategies in Tissue Engineering" organized by WITE e.V. (Würzburger Initiative Tissue Engineering) the NIH and Harvard Medical School, Würzburg, Germany (2006).

109. G. E. Wnek, M. E. Carr, D. G. Simpson, and G. L. Bowlin, Nano. Lett. 3, 213 (2003).

110. I. C. Um, D. Fang, B. S. Hsiao, A. Okamoto, and B. Chu, Biomacromolecules 5, 1428 (2004).

111. W. K. Son, J. H. Youk, and W. H. Park, Biomacromolecules 5, 197 (2004).

112. Z. Ma, W. He, T. Yong, and S. Ramakrishna, Tissue Eng. 11, 1149 (2005).

113. W. He, T. Yong, W. E. Teo, Z. Ma, and S. Ramakrishna, Tissue Eng. 11, 1574 (2005).

114. S. Zhong, W. E. Teo, X. Zhu, R. Beuerman, S. Ramakrishna, and L. Y. Yung, Biomacromolecules 6, 2998 (2005).

115. Y. Z. Zhang, J. Venugopal, Z. M. Huang, C. T. Lim, and S. Ramakrishna, Biomacromolecules 6, 2583 (2005).

116. S.-M. Niemelä, I. Ikäheimo, M. Koskela, M. Veiranto, E. Suokas, P. Törmälä, T. Waris, N. Ashammakhi, and H. Syrjälä, J. Biomed. Mater. Res. 76, 8 (2006)

117. R. Huolman and N. Ashammakhi, J. Craniofac. Surg. (2006), submitted.

118. M. Veiranto, E. Suokas, N. Ashammakhi, and P. Törmälä, Adv. Exp. Med. Biol. 553, 197 (2004).

119. L. Nikkola, P. Viitanen, and N. Ashammakhi, in 6th International Symposium on Frontiers in Biomedical Polymers (FBPS'05), Granada, Spain (2005), p. 45.

120. H. Korkka, M. Veiranto, L. Nikkola, and N. Ashammakhi, UK Society for Biomaterials, Manchester (2006).

121. P. Viitanen, E. Suokas, P. Törmälä, and N. Ashammakhi, J. Mater. Sci. Mater. Med. (2006), accepted.

122. N. Ashammakhi and P. Törmälä, J. Craniofac. Surg. 15, 897 (2004).

123. A. Piras, L. Nikkola, F. Chiellini, E. Chiellini, and N. Ashammakhi, in 20th European Conference on Biomaterials, European Society of Biomaterials (ESB), Cité des Congrès, Nantes, France (2006).

124. A. Piras, L. Nikkola, F. Chiellini, E. Chiellini, and N. Ashammakhi, J. Nanosci. Nanotechnol. (2006).

125. J. Zeng, A. Aigner, F. Czubayko, T. Kissel, J. H. Wendorff, and A. Greiner, Biomacromolecules 6, 1484 (2005)

126. G. Verreck, I. Chun, J. Rosenblatt, J. Peeters, A. Van Dijck, J. Mensch, M. Noppe, and M. E. Brewster, J. Control. Release 92, 349 (2003).

127. I. G. Loscertales, A. Barrero, I. Guerrero, R. Cortijo, M. Marquez, and A. M. Ganan-Calvo, Science 295, 1695 (2002).
128. Z. Sun, E. Zussman, A. Yarin, J. Wendorff, and A. Greiner, $A d v$. Mater. 15, 1929 (2003).

129. Y. Ito, H. Hasuda, M. Kamitakahara, C. Ohtsuki, M. Tanihara, I. K. Kang, and O. H. Kwon, J. Biosci. Bioeng. 100, 43 (2005).

130. X. M. Mo, C. Y. Xu, M. Kotaki, and S. Ramakrishna, Biomaterials 25,1883 (2004)

131. L. S. Nair, S. Bhattacharyya, J. D. Bender, Y. E. Greish, P. W Brown, H. R. Allcock, and C. T. Laurencin, Biomacromolecules 5 , 2212 (2004).

132. C. Xu, R. Inai, M. Kotaki, and S. Ramakrishna, Tissue Eng. 10 , 1160 (2004)

133. R. El Kenawy, J. M. Layman, J. R. Watkins, G. L. Bowlin, J. A. Matthews, D. G. Simpson, and G. E. Wnek, Biomaterials 24, 907 (2003).

134. L. Buttafoco, N. G. Kolkman, P. Engbers-Buijtenhuijs, A. A. Poot, P. J. Dijkstra, I. Vermes, and J. Feijen, Biomaterials 27, 724 (2006).

135. S. A. Riboldi, M. Sampaolesi, P. Neuenschwander, G. Cossu, and S. Mantero, Biomaterials 26, 4606 (2005).

136. P. Wutticharoenmongkol, N. Sanchavanakit, P. Pavasant, and P. Supaphol, Macromol. Biosci. 6, 70 (2006).

137. K. Kim, M. Yu, X. Zong, J. Chiu, D. Fang, J.-S. Seo, B. S. Hsiao, and M. Hadjiargyrou, Biomaterials 24, 4977 (2003).

138. M. A. Tria, M. Fusco, G. Vantini, and R. Mariot, Exp. Neurol. 127 , 178 (1994).

139. C. H. Kim, M. S. Khil, H. Y. Kim, H. U. Lee, and K. Y. Jahng, J. Biomed. Mater. Res. (2006), in press.

140. M. Shin, H. Yoshimoto, and J. P. Vacanti, Tissue Eng. 10, 33 (2004).

141. T. J. Webster, R.W. Siegel, and R. Bizios, Biomaterials 20, 1221 (1999).

142. A. Subramanian, H. Y. Lin, D. Vu, and G. Larsen, Biomed. Sci. Instrum. 40, 117 (2004).

143. S. R. Bhattarai, N. Bhattarai, H. K. Yi, P. H. Hwang, D. I. Cha, and H. Y. Kim, Biomaterials 25, 2595 (2004).

144. P. B. Vanwachem, M. J. A. Vanluyn, L. Damink, P. J. Dijkstra, J. Feijen, and P. Nieuwenhuis, J. Biomed. Mater. Res. 28, 353 (1994).

145. W. K. Son, J. H. Youk, T. S. Lee, and W. H. Park, Polymer 45 , 2959 (2004)

146. G. Viswanathan, S. Murugesan, V. Pushparaj, O. Nalamasu, P. M. Ajayan, and R. J. Linhardt, Biomacromolecules 7, 415 (2006).

147. K. S. Rho, L. Jeong, G. Lee, B. M. Seo, Y. J. Park, S. D. Hong, S. Roh, J. J. Cho, W. H. Park, and B.-M. Min, Biomaterials 27, 1452 (2006).

148. B. Min, S. W. Lee, J. N. Lim, Y. You, T. S. Lee, P. H. Kang, and W. H. Park, Polymer 45, 7137 (2004).

149. X. Geng, O.-H. Kwon, and J. Jang, Biomaterials 26, 5427 (2005).

150. H. Ylikauppila, L. Nikkola, M. Gomes, R. Reis, and N. Ashammakhi, FiberMed 2006-Fibrous Products in Medical and Health Care, Tampere, Finland (2006).

151. M. Li, Y. Guo, Y. Wei, A. G. Macdiarmid, and P. I. Lelkes, Biomaterials 27, 2705 (2006).

152. Y. Zhang, H. Ouyang, C. T. Lim, S. Ramakrishna, and Z.-M. Huang, J. Biomed. Mater. Res. 72, 156 (2005).

Received: 23 April 2006. Revised/Accepted: 29 May 2006. 